\title{
Formation of Dense and High-Aspect-Ratio Iron Oxide Nanowires by Water Vapor-Assisted Thermal Oxidation and Their $\mathrm{Cr}(\mathrm{VI})$ Adsorption Properties
}

\author{
Faisal Budiman, Wai Kian Tan,* Go Kawamura, Hiroyuki Muto, Atsunori Matsuda,
} Khairunisak Abdul Razak, and Zainovia Lockman*

Cite This: ACS Omega 2021, 6, 28203-28214

Read Online

ABSTRACT: Coral-like and nanowire (NW) iron oxide nanostructures were produced at 700 and $800{ }^{\circ} \mathrm{C}$, respectively, through thermal oxidation of iron foils in air- and water vapor-assisted conditions. Water vapor-assisted thermal oxidation at $800{ }^{\circ} \mathrm{C}$ for $2 \mathrm{~h}$ resulted in the formation of highly crystalline $\alpha$ - $\mathrm{Fe}_{2} \mathrm{O}_{3}$ NWs with good foil surface coverage, and we propose that their formation was due to a stressdriven surface diffusion mechanism. The $\mathrm{Cr}(\mathrm{VI})$ adsorption property of an aqueous solution on $\alpha-\mathrm{Fe}_{2} \mathrm{O}_{3} \mathrm{NWs}$ was also evaluated after a contact time of $90 \mathrm{~min}$. The NWs had a removal efficiency of $97 \%$ in a $225 \mathrm{mg} / \mathrm{L} \mathrm{Cr}(\mathrm{VI})$ solution $\left(\mathrm{pH} 2,25^{\circ} \mathrm{C}\right)$. The kinetic characteristic of the adsorption was fitted to a pseudo-second-order kinetic model, and isothermal studies indicated that the $\alpha$ - $\mathrm{Fe}_{2} \mathrm{O}_{3} \mathrm{NWs}$ exhibited an adsorption capacity of $66.26 \mathrm{mg} / \mathrm{g}$. We also investigated and postulated a mechanism of the $\mathrm{Cr}(\mathrm{VI})$ adsorption in an aqueous solution of $\alpha-\mathrm{Fe}_{2} \mathrm{O}_{3} \mathrm{NWs}$.

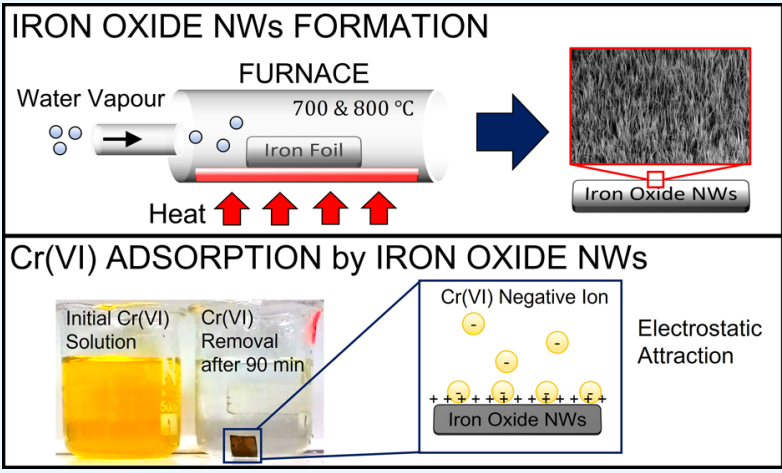

\section{INTRODUCTION}

Chromium has oxidation states from (II) to (VI) but is the most stable in its trivalent (III) $[\mathrm{Cr}$ (III)] and hexavalent (VI) $[\mathrm{Cr}(\mathrm{VI})]$ forms; however, $\mathrm{Cr}(\mathrm{VI})$ rarely occurs naturally and originates from anthropogenic sources. Unlike $\mathrm{Cr}(\mathrm{III}), \mathrm{Cr}(\mathrm{VI})$ is toxic and carcinogenic. ${ }^{1,2}$ Excessive inhalation of $\mathrm{Cr}(\mathrm{VI})$ can lead to lung cancer, ${ }^{3}$ direct skin contact with it may result in dermatitis, ${ }^{4}$ and when ingested, it can cause organ damage. ${ }^{5}$ $\mathrm{Cr}$ (VI) compounds are, nonetheless, extremely important for electroplating, steel manufacturing, leather tanning, and textile production. ${ }^{6}$ Inevitably, wastewater from these processes contains large amounts of $\mathrm{Cr}(\mathrm{VI})$, and unless properly treated, it can enter surface waters, causing harm to aquatic life and possibly entering the food chain. The World Health Organization has recommended that $\mathrm{Cr}(\mathrm{VI})$ concentrations in water should not exceed $0.05 \mathrm{mg} / \mathrm{L}^{7}$ therefore, total removal of $\mathrm{Cr}(\mathrm{VI})$ from industrial wastewater is crucial in order to prevent surface water concentrations exceeding this level.

There are several accepted methods for removing $\mathrm{Cr}(\mathrm{VI})$, which typically exists as highly soluble and toxic chromate anions $\left(\mathrm{HCrO}_{4}{ }^{-}\right.$or $\mathrm{Cr}_{2} \mathrm{O}_{7}{ }^{2-}$ ), from industrial wastewater: photocatalytic reduction, ${ }^{6,8-10}$ chemical precipitation, ${ }^{11}$ electrokinetic remediation, ${ }^{12}$ membrane filtration, ${ }^{13,14}$ and adsorption. $^{15-17}$ Among these methods, adsorption is especially appealing, as it is very effective at removing $\mathrm{Cr}(\mathrm{VI}) .{ }^{18}$ The adsorption process requires a solid surface (i.e., an adsorbent) with a large surface area for the species to be adsorbed (i.e., an adsorbate) to attach to, either by physical or chemical processes, for which in here, the use of a nanosized material will be beneficial for providing the surface area. Nanostructured materials can be defined as a material having an internal nanostructure or a surface nanostructure and present themselves as attractive large-surface-area adsorbents for this purpose, of which one-dimensional nanostructures, such as nanowires (NWs), are particularly effective.

Iron oxide is a compound material, largely found as hematite $\left(\alpha-\mathrm{Fe}_{2} \mathrm{O}_{3}\right)$, magnetite $\left(\mathrm{Fe}_{3} \mathrm{O}_{4}\right)$, wüstite $\left(\mathrm{Fe}_{1-x} \mathrm{O}\right)$, and maghemite $\left(\gamma-\mathrm{Fe}_{2} \mathrm{O}_{3}\right),{ }^{19}$ which has attracted attention as an adsorbent due to its ability to remove various types of heavymetal ions. ${ }^{20-24}$ Recent studies have demonstrated that $\alpha$ $\mathrm{Fe}_{2} \mathrm{O}_{3}$ has a high adsorption capability, which occurs through a chemisorption process involving the hydroxyl group on its surface. ${ }^{25}$ Ren et al. investigated $\alpha-\mathrm{Fe}_{2} \mathrm{O}_{3}$ in a fibrous form for

Received: August 10, 2021

Accepted: October 5, 2021

Published: October 15, 2021 
$\mathrm{Cr}(\mathrm{VI})$ ion removal and reported that the porous fiber-like morphology of $\alpha-\mathrm{Fe}_{2} \mathrm{O}_{3}$ exhibited excellent adsorption of $\mathrm{Cr}(\mathrm{VI})$ from water, with rapid adsorption kinetics, high adsorption capacity, and good reusability. ${ }^{26}$ In view of these results, we attempted to prepare $\alpha-\mathrm{Fe}_{2} \mathrm{O}_{3}$ NWs through thermal oxidation of iron foils and investigated the sample's ability to remove $\mathrm{Cr}(\mathrm{VI})$ from aqueous solutions.

Thermal oxidation can be used to produce thin-film oxides composed of NWs. ${ }^{27}$ Although there are various other ways of producing $\alpha-\mathrm{Fe}_{2} \mathrm{O}_{3}$ NWs, such as electrospinning, ${ }^{28,29}$ hydrothermal, ${ }^{30}$ and nanocasting methods, ${ }^{31}$ which produce NWs with a uniform diameter and length, they are known to be time-consuming, and post-annealing treatments are required for crystalline oxide formation. Thermal oxidation presents a simpler approach to forming surface oxide layers, and through careful control of the oxidation parameters, e.g., oxidation temperature, ${ }^{32-35}$ unique nanostructures can be produced. Apart from temperature, the oxidation time and environment also affect the growth of NWs. ${ }^{36}$ Our previous work explored the formation of iron oxide NWs by thermal oxidation in water vapor-assisted conditions. ${ }^{33,35}$ The presence of water vapor during oxidation was found to induce more densely packed nanostructures with a uniform distribution compared with those under dry-air conditions; however, this work was performed at lower temperatures $\left(400-500{ }^{\circ} \mathrm{C}\right)$. Upon oxidation of iron at high temperatures, oxide scales consisting of multilayered oxides are formed. From the $\mathrm{Fe}-\mathrm{O}$ phase diagram, oxidation of iron at either below or above $570{ }^{\circ} \mathrm{C}$ leads to the formation of different Fe oxide layers. Although our previous studies reported the formation of one- (1D) and two-dimensional iron oxide nanostructures, detailed investigations at higher temperature regimes $\left(>570{ }^{\circ} \mathrm{C}\right)$ including the formation mechanism and $\mathrm{Cr}(\mathrm{VI})$ removal properties are not elucidated.

In this study, we investigated the formation of iron oxide nanostructures by thermal oxidation under water vaporassisted conditions at high temperature regimes (i.e., 700 and $800{ }^{\circ} \mathrm{C}$ ) and assessed the $\mathrm{Cr}(\mathrm{VI})$ removal capability of the samples. The growth of iron oxide NWs at these temperature regions under water vapor was systematically investigated, and the formation mechanism of high-aspect-ratio $1 \mathrm{D} \mathrm{Fe}_{2} \mathrm{O}_{3} \mathrm{NWs}$ and their $\mathrm{Cr}(\mathrm{VI})$ adsorption properties are reported. In regard to $\mathrm{Cr}(\mathrm{VI})$ adsorption behavior, the kinetic and equilibrium models were investigated, enabling the determination of the dynamic adsorptive property and the loading capacity of the formed $\mathrm{Fe}_{2} \mathrm{O}_{3} \mathrm{NWs}$. We found that the adsorptive behavior of the NW sample follows the Langmuir and pseudo-secondorder kinetic models. Therefore, investigating these hightemperature oxidations further may result in novel and potentially useful nanostructures for various applications, including adsorption of toxic pollutants from contaminated water.

\section{RESULTS AND DISCUSSION}

2.1. Morphological Observations. FESEM images of the surface morphologies of the foils oxidized in dry air and water vapor at 700 and $800{ }^{\circ} \mathrm{C}$ are presented as Figure 1 . It can be observed that different oxidation temperatures resulted in different morphologies, and it can be due to the dissimilarity of created stresses when the oxidation temperature is different. At $700{ }^{\circ} \mathrm{C}$, the surface oxidization exhibited a coral-like structure, which was larger on the water vapor-oxidized sample than on the air-oxidized sample as shown in Figure 1a,b, respectively.

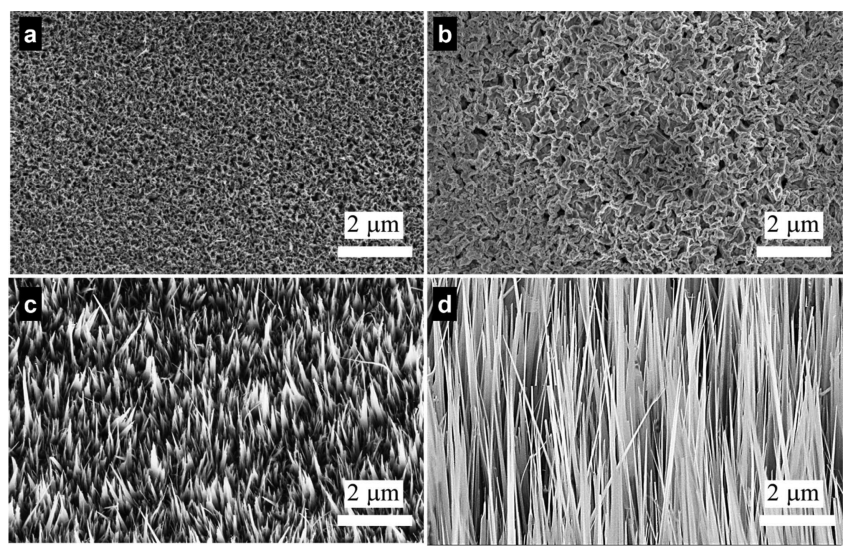

Figure 1. FESEM images of iron foils oxidized for $2 \mathrm{~h}$ in (a) $700{ }^{\circ} \mathrm{C}$ air, (b) $700{ }^{\circ} \mathrm{C}$ water vapor, (c) $800{ }^{\circ} \mathrm{C}$ air, and (d) $800{ }^{\circ} \mathrm{C}$ water vapor.

Micrographs of the foils oxidized at $800{ }^{\circ} \mathrm{C}$ in dry air and water vapor are presented in Figure 1c,d, respectively, and they show that the NWs formed on these foils were finer and longer (up to $20 \mu \mathrm{m}$ ) when oxidized in water vapor. This demonstrated that water vapor-assisted thermal oxidation strongly influenced the aspect ratio of the NWs.

To further investigate the effect of water vapor on the growth of the NWs, various oxidation durations were applied at $800{ }^{\circ} \mathrm{C}$, and the resulting surface morphologies are illustrated in Figure 2. Interestingly, the NWs were formed after only 5 min of oxidation, as illustrated in Figure 2a, but the areal density was initially low with only sparse NWs formed on the foil surface. Here, areal density was defined as the number of NWs per measured area in an FESEM image. Extending the oxidation time to 15,30 , and $60 \mathrm{~min}$ increased the areal density of the NWs, as illustrated in Figure $2 b-d$, respectively, and oxidation for $120 \mathrm{~min}$ resulted in the formation of a dense, homogeneous NW surface, as illustrated in Figure 2e; therefore, we concluded that both the length and diameter of the NWs increased with increasing oxidation time. A summary of the morphological observations at $800{ }^{\circ} \mathrm{C}$, including those of the length, aspect ratio, and areal density as a function of the oxidation time, is presented in Figure 3. These results indicate that controlled formation of $\alpha-\mathrm{Fe}_{2} \mathrm{O}_{3}$ NWs can be achieved by controlling the oxidation time during water vapor-assisted thermal oxidation.

To gain an insight into the crystallinity of the NWs, we performed HR-TEM observations of a single $\alpha-\mathrm{Fe}_{2} \mathrm{O}_{3} \mathrm{NW}$ obtained through water vapor-assisted thermal oxidation at 800 ${ }^{\circ} \mathrm{C}$ for $2 \mathrm{~h}$. The subsequent HR-TEM image is presented in Figure $4 \mathrm{a}$, which indicates that the diameters of the bottom and tip of the nanowire were approximately 60 and $5 \mathrm{~nm}$, respectively. The image also shows that the measured $d$ spacing was approximately $0.25 \mathrm{~nm}$, which is in accordance with the (110) plane of $\alpha-\mathrm{Fe}_{2} \mathrm{O}_{3}$. The tapered structure of the NWs was confirmed by the FESEM image in Figure $4 \mathrm{~b}$.

2.2. Crystal Phase of the $\alpha-\mathrm{Fe}_{2} \mathrm{O}_{3}$ NWs. Figure 5a presents the XRD patterns of the iron foils oxidized at $800{ }^{\circ} \mathrm{C}$ for $2 \mathrm{~h}$ in air and water vapor. The XRD results indicated that the NWs consisted of crystalline structures with peaks indexed to hematite $\left(\alpha-\mathrm{Fe}_{2} \mathrm{O}_{3}\right)$ (ICDD no. 98-001-2733) and magnetite $\left(\mathrm{Fe}_{3} \mathrm{O}_{4}\right.$ ) (ICDD no. 98-001-7319). It has been previously reported that following the thermal oxidation of iron, the outermost oxide layer is $\alpha-\mathrm{Fe}_{2} \mathrm{O}_{3}$, and the underlying oxide is 

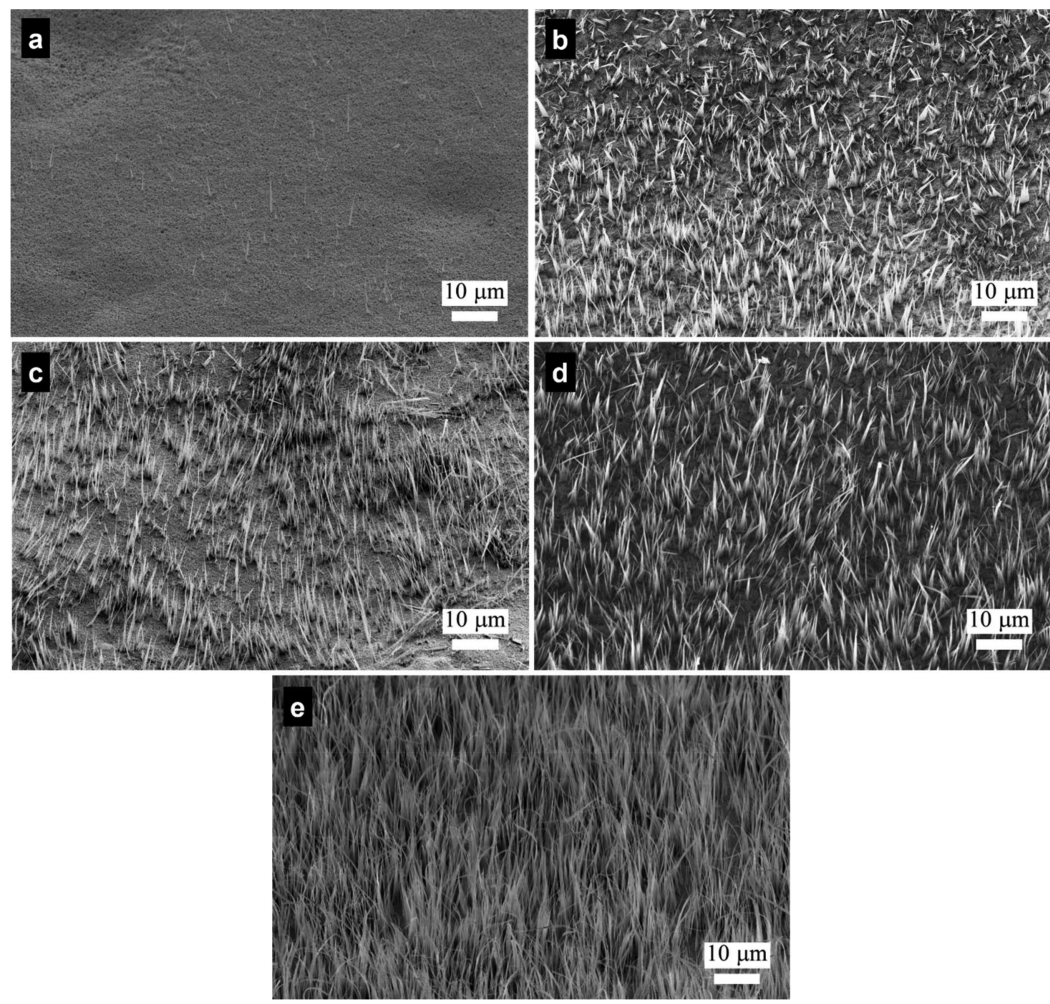

Figure 2. FESEM images of the oxidized iron at $800{ }^{\circ} \mathrm{C}$ in water vapor for (a) 5, (b) 15, (c) 30, (d) 60, and (e) $120 \mathrm{~min}$.
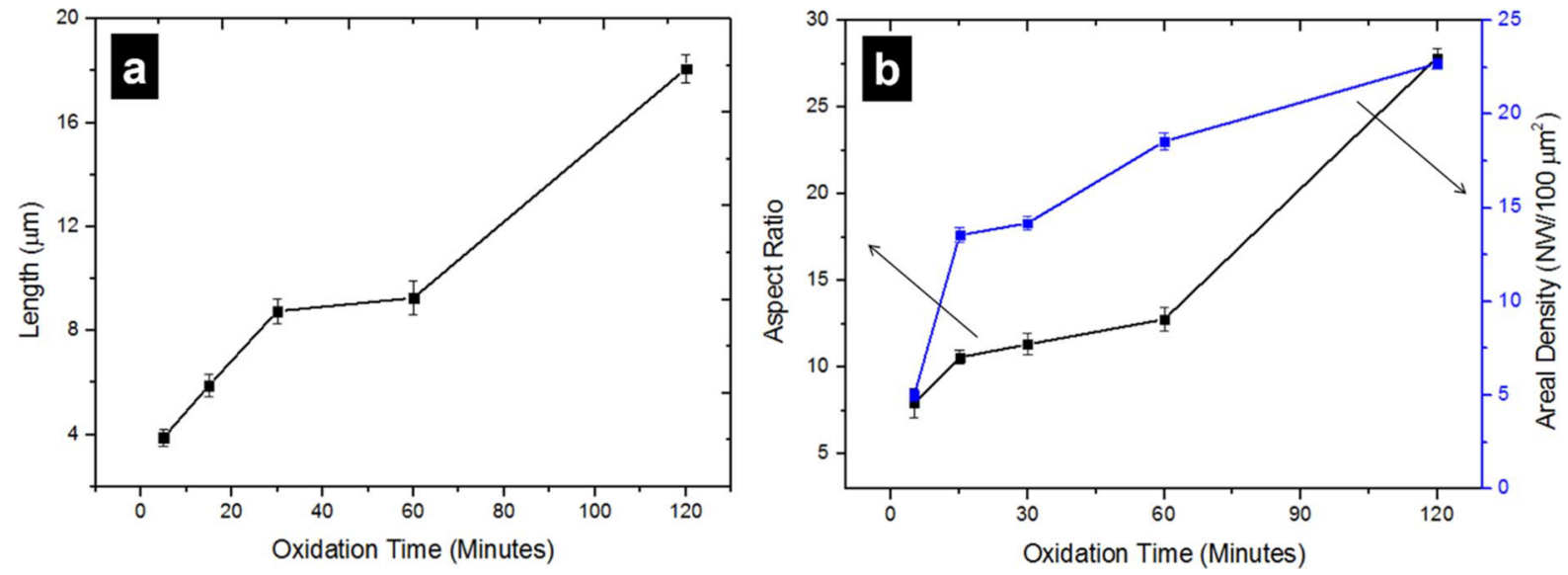

Figure 3. Quantitative analysis of (a) length, (b) aspect ratio, and areal density of the iron foils oxidized at $800{ }^{\circ} \mathrm{C}$ in water vapor for $5-120$ min.

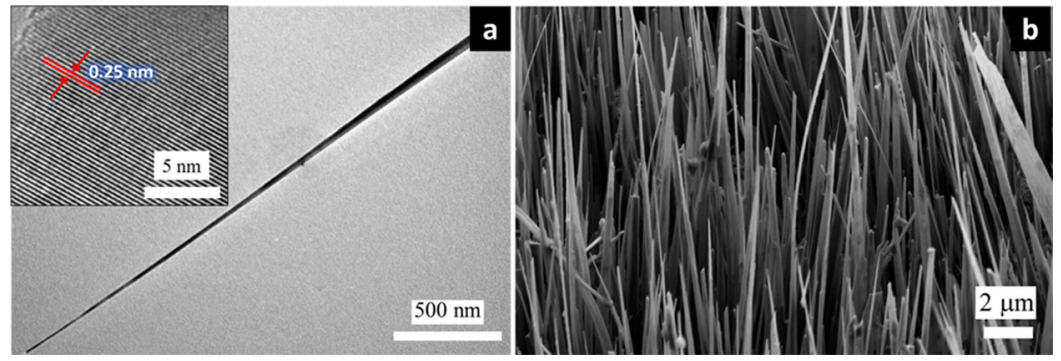

Figure 4. (a) HR-TEM image of a single $\alpha-\mathrm{Fe}_{2} \mathrm{O}_{3} \mathrm{NW}$ and (b) FESEM image of iron foil oxidized at $800{ }^{\circ} \mathrm{C}$ for $2 \mathrm{~h}$ in water vapor.

$\mathrm{Fe}_{3} \mathrm{O}_{4}{ }^{38}$ To verify this, we performed Raman spectroscopy. The Raman results are presented in Figure $5 \mathrm{~b}$ and include bands at 227, 245, 293, 412, 499, and $612 \mathrm{~cm}^{-1}$, which correspond to the $\alpha-\mathrm{Fe}_{2} \mathrm{O}_{3}$ phase. ${ }^{39}$ Owing to the low penetration depth of a Raman laser compared with XRD, we concluded that the outermost oxide layer was $\alpha-\mathrm{Fe}_{2} \mathrm{O}_{3}$. Also, although the water vapor-assisted oxidation resulted in a 

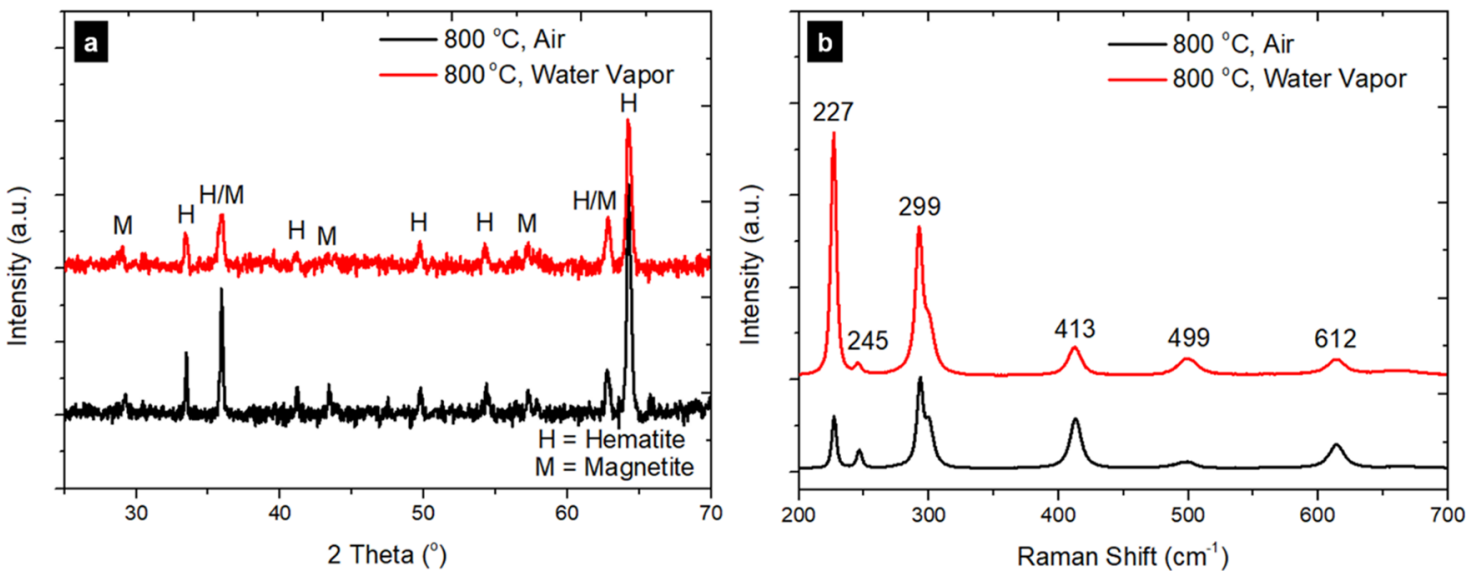

Figure 5. (a) XRD patterns and (b) Raman spectra of the iron foils oxidized at $800{ }^{\circ} \mathrm{C}$ for $2 \mathrm{~h}$ in air and water vapor.

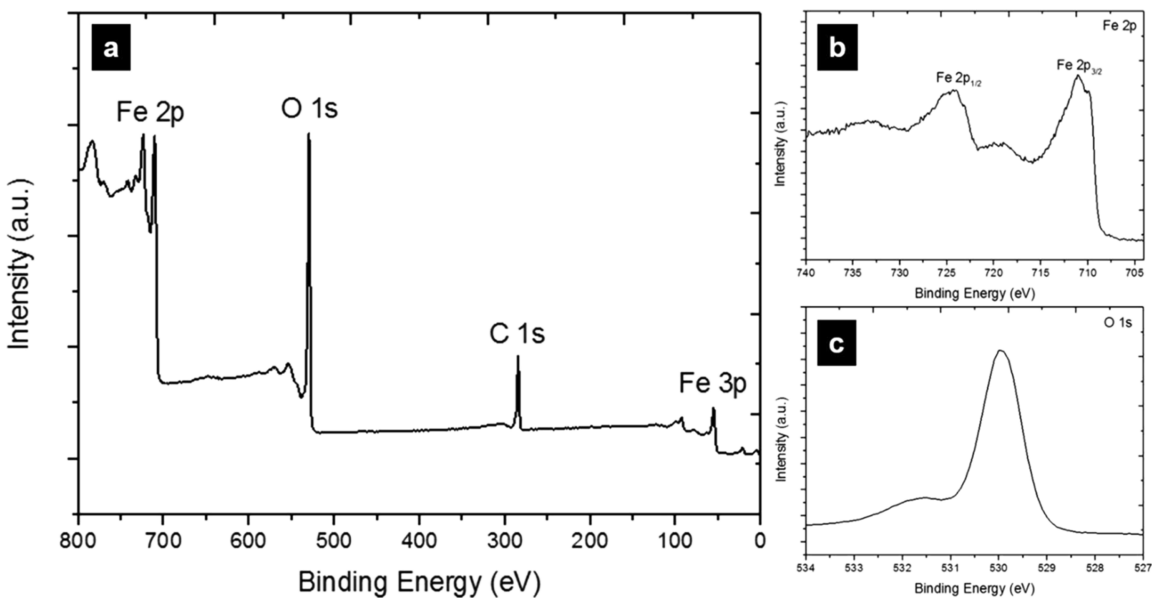

Figure 6. (a) Wide-scan, (b) Fe 2p, and (c) O 1s XPS spectra of iron foils oxidized at $800{ }^{\circ} \mathrm{C}$ in water vapor for $2 \mathrm{~h}$.

denser formation of NWs, the outer $\alpha-\mathrm{Fe}_{2} \mathrm{O}_{3}$ phase oxide layer was observed in the air-oxidized samples.

The surface elemental compositions of the foils oxidized at $800{ }^{\circ} \mathrm{C}$ for $2 \mathrm{~h}$ in water vapor were confirmed using XPS measurements. The obtained XPS spectrum is presented in Figure 6 and indicates the presence of $\mathrm{Fe}, \mathrm{O}$, and $\mathrm{C}$ in the $\alpha$ $\mathrm{Fe}_{2} \mathrm{O}_{3}$ NWs, as shown in the wide-scan spectrum in Figure 6a. Figure $6 \mathrm{~b}$ presents a high-resolution spectrum of $\mathrm{Fe} 2 \mathrm{p}$, including two peaks at 724.4 and $709.9 \mathrm{eV}$, which correspond to $\mathrm{Fe} 2 \mathrm{p}_{1 / 2}$ and $\mathrm{Fe} 2 \mathrm{p}_{3 / 2}$, respectively. A binding energy difference of $14.5 \mathrm{eV}$ and the absence of a peak at $719.0 \mathrm{eV}$ suggested a predominant $\mathrm{Fe}^{3+}$ oxidation state, which further verified the presence of the $\alpha-\mathrm{Fe}_{2} \mathrm{O}_{3}$ phase. ${ }^{40}$ The $\mathrm{O} 1 \mathrm{~s}$ peak, shown in Figure 6c, with a binding energy of $530 \mathrm{eV}$ corresponds to the $\mathrm{O}^{2-}$ oxidation state in the oxide, and the second broad peak at $531.5 \mathrm{eV}$ corresponds to the adsorbed oxygen or hydroxyl ions. ${ }^{40}$ These XPS results further indicated that the outermost layer generated on the surface of the oxidized foils consisted of $\alpha-\mathrm{Fe}_{2} \mathrm{O}_{3}$.

2.3. Growth Mechanism of the NWs. 2.3.1. Initial Oxidation Stage. During dry-air thermal oxidation, the diffusion process is initiated by the chemisorption of oxygen onto the surface of the iron foil, forming a chemisorbed layer, which is then followed by the ionization of oxygen, forming $\mathrm{O}^{2-}$ (eq 1). The ionization of oxygen generates an electric field on the surface of the foil and triggers the oxidation of $\mathrm{Fe}$ (eq 2 ). Overall, the reciprocal diffusion of oxygen and iron promotes the buildup of the oxide layer and forms a thin layer of iron oxide.

$$
\begin{aligned}
& \mathrm{O}_{2}(\mathrm{~g}) \rightarrow \mathrm{O}_{2}(\text { ads }) \rightarrow 2 \mathrm{O}(\text { ads })=2 \mathrm{O}^{-}(\text {chem })+2 \mathrm{~h}^{\bullet} \\
& \quad \rightarrow 2 \mathrm{O}^{2-}(\text { latt })+4 \mathrm{~h}^{\bullet} \\
& \mathrm{Fe} \rightarrow \mathrm{Fe}^{2+}+2 \mathrm{e}^{-}
\end{aligned}
$$

During water vapor-assisted thermal oxidation, the previously stable, ${ }^{41}$ adsorbed water molecule dissociates as vapor (eqs 3 and 4).

$$
\begin{aligned}
& \mathrm{H}_{2} \mathrm{O}(\mathrm{g}) \rightarrow \mathrm{H}_{2} \mathrm{O} \text { (ads) } \\
& \mathrm{H}_{2} \mathrm{O} \rightarrow \mathrm{H}_{2}+\frac{1}{2} \mathrm{O}_{2}
\end{aligned}
$$

It has been reported that oxidation under water vapor conditions is accelerated compared with that in dry air, which may be due to the incorporation of a proton, accompanied by electrons, within the oxide scale during oxide growth. Fujii and Meussner reported that during oxidation in water vapor, the desorption of hydrogen from the oxide surface occurred (eq $5)$; this resulted in partial dissolution in the oxide ${ }^{42}$ (eq 6). The small ionic radius of $\mathrm{H}$ atoms compared with those of $\mathrm{Fe}$ and $\mathrm{O}^{43}$ means that $\mathrm{H}$ can interstitially bind with $\mathrm{O}$ as $\mathrm{OH}_{\mathrm{o}}$ in the oxide. The creation of such defects, compensated by electron deficiency, metal vacancies, and oxygen interstitials, 
may in turn increase the oxidation rate, resulting in the increased rate of NW formation observed in this study.

$$
\begin{aligned}
& 2 \mathrm{H}_{i}{ }^{\bullet}+2 \mathrm{e}^{-} \rightarrow \mathrm{H}_{2} \\
& \mathrm{H}_{2} \mathrm{O}(\text { ads }) \rightarrow \mathrm{OH}_{\mathrm{o}}{ }^{\prime}+\mathrm{H}_{i}{ }^{\bullet}
\end{aligned}
$$

2.3.2. Formation of the Oxide Scale. The interaction of iron with reactive oxidative gases at high temperatures resulted in the formation of an oxide scale on the foil surface, as illustrated in the cross-sectional FESEM image in Figure 7.

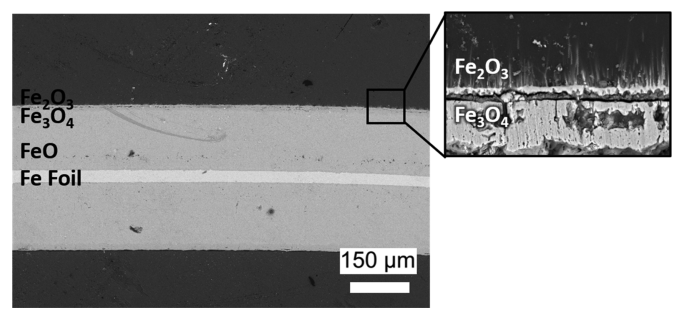

Figure 7. Cross-sectional FESEM image of iron foils oxidized at 800 ${ }^{\circ} \mathrm{C}$ in water vapor for $2 \mathrm{~h}$.

This scale was composed of multiple layers of oxides, an outer layer of $\alpha-\mathrm{Fe}_{2} \mathrm{O}_{3}$ and an inner layer of $\mathrm{Fe}_{1-x} \mathrm{O}$ and $\mathrm{Fe}_{3} \mathrm{O}_{4}$, depending on the oxidization temperature. $\mathrm{Fe}_{1-x} \mathrm{O}$ is thermodynamically unstable below $570{ }^{\circ} \mathrm{C}$; thus, it was likely to be present during oxidation at the temperatures used in this study. The cross-sectional FESEM image in Figure 7 indicates that the $\mathrm{Fe}_{1-x} \mathrm{O}$ layer was thicker than the $\mathrm{Fe}_{3} \mathrm{O}_{4}$ and $\alpha-\mathrm{Fe}_{2} \mathrm{O}_{3}$ layers after oxidation at $800{ }^{\circ} \mathrm{C}$ for $2 \mathrm{~h}$ under water vaporassisted conditions. $\mathrm{Fe}_{1-x} \mathrm{O}$ is a nonstoichiometric compound with rich metal vacancies, which, through phase transformation, aids the growth of other phases during oxidation. Phase formation is thought to follow eq 7, with $\mathrm{Fe}_{1-x} \mathrm{O}$ being transformed first to $\mathrm{Fe}_{3} \mathrm{O}_{4}$ and then to $\alpha-\mathrm{Fe}_{2} \mathrm{O}_{3}$. The phase transformations during oxidation in dry air and water vapor are presented in Table 1.

$$
\mathrm{Fe} \rightarrow \mathrm{FeO} \rightarrow \mathrm{Fe}_{3} \mathrm{O}_{4} \rightarrow \alpha-\mathrm{Fe}_{2} \mathrm{O}_{3}
$$

2.3.3. Oxidation Growth Stress. The cross-sectional FESEM images in Figure 7 indicate that the surface region of the iron was composed of layered oxides in various phases, the presence of which generated stress within the oxide scale. During oxidation, thermal expansion leads to an increase in volume, which also contributes to oxide growth; however, this expansion resulted in a volume discrepancy of the iron and iron oxide, which induced a stress region at the metal-oxide interface. This caused the surface scale to be either in high compressive or tensile stress, especially at the interface regions; if the expansion of the outer oxide layer is larger than that of the oxide layer underneath, then a compressive stress develops (Pilling-Bedworth ratio $>1$ ) in the upper oxide and a tensile stress develops in the underlying oxide. This discrepancy alters the diffusion rate of the growing species, leading to preferential growth of the oxide at the oxide-air interface in the $c$-axis direction. $^{38}$

The relaxation of the generated stresses resulted in the growth of NWs at the surface by a mechanism illustrated in Figure 8. During the thermal oxidation process, Fe species diffuse and are accelerated across the oxide layer before nucleating on $\alpha-\mathrm{Fe}_{2} \mathrm{O}_{3}$ grains through surface diffusion. This continuous and fast diffusion led to NW growth along the $c$ axis, which generated elongated oxide nanostructures, i.e., NWs. Observations under FESEM evidenced this phenomenon, with the nucleation and surface diffusion processes clearly seen in Figure 9a,b, respectively.

2.4. Evaluation of $\mathrm{Cr}(\mathrm{VI})$ Adsorption Using the $\alpha$ $\mathrm{Fe}_{2} \mathrm{O}_{3}$ NWs. We then evaluated the $\mathrm{Cr}(\mathrm{VI})$ adsorption properties of the NWs using the $\alpha-\mathrm{Fe}_{2} \mathrm{O}_{3} \mathrm{NWs}$ obtained after thermal oxidation at $800{ }^{\circ} \mathrm{C}$, both in air and water vapor. Pure iron foil was also assessed as a control sample. As shown in Figure 10a, the removal efficiency of $\mathrm{Cr}(\mathrm{VI})$ with an initial concentration at $200 \mathrm{mg} / \mathrm{L}$ was $13.5,71$, and $95 \%$ for pure iron and the samples oxidized in air and in water vapor atmospheres, respectively. These results indicate that the presence of water vapor promoted the formation of NWs with a larger surface area in comparison to those generated in air.

Moreover, further assessment of the samples obtained after water vapor-assisted thermal oxidation at $800{ }^{\circ} \mathrm{C}$ with various concentrations of $\mathrm{Cr}(\mathrm{VI})$ between 225 and $300 \mathrm{mg} / \mathrm{L}$ was conducted at room temperature. The results obtained are shown in Figure 10b, exhibiting a high $\mathrm{Cr}(\mathrm{VI})$ removal efficiency of $>90 \%$ for each concentration. Here, we varied the concentration of the adsorbate according to the adsorption limit of the sample for evaluating the kinetic and equilibrium behavior. An equilibrium was reached after $90 \mathrm{~min}$ of contact between the NWs and the $\mathrm{Cr}(\mathrm{VI})$ solution. The adsorption profiles exhibited similar patterns across the various $\mathrm{Cr}(\mathrm{VI})$ solutions.

A unique amphoteric property of metal oxide offers the flexibility on shifting the surface charge of iron oxide, hence allowing either anion or cation adsorption from aqueous environments. The mechanism of those adsorptions is based on electrostatic attraction, ${ }^{44}$ and it is $\mathrm{pH}$-dependent. ${ }^{14,45}$ The nature of $\mathrm{Cr}(\mathrm{VI})$ species is mostly found as a negative ion. ${ }^{46}$

\begin{tabular}{|c|c|c|}
\hline & Oxidation reaction in dry air & Oxidation reaction in water vapor \\
\hline Air condition & $\mathrm{O}_{2}+4 \bar{e} \rightarrow 2 \mathrm{O}^{2-}$ & $\mathrm{H}_{2} \mathrm{O} \rightarrow \mathrm{OH}_{o}^{\prime}+\mathrm{H}_{i}^{\cdot}$ \\
\hline $\begin{array}{l}\text { Hematite } \\
\left(\alpha-\mathrm{Fe}_{2} \mathrm{O}_{3}\right)\end{array}$ & $2 \mathrm{Fe}^{3+}+3 \mathrm{O}^{2-} \rightarrow \mathrm{Fe}_{2} \mathrm{O}_{3}$ & $2 \mathrm{Fe}^{3+}+3 \mathrm{OH}^{-} \rightarrow \mathrm{Fe}_{2} \mathrm{O}_{3}+3 \mathrm{H}^{+}$ \\
\hline $\begin{array}{c}\text { Magnetite } \\
\left(\mathrm{Fe}_{3} \mathrm{O}_{4}\right)\end{array}$ & $2 \mathrm{Fe}^{3+}+\mathrm{Fe}^{2+}+4 \mathrm{O}^{2-} \rightarrow \mathrm{Fe}_{3} \mathrm{O}_{4}$ & $2 \mathrm{Fe}^{3+}+\mathrm{Fe}^{2+}+4 \mathrm{OH}^{-} \rightarrow \mathrm{Fe}_{3} \mathrm{O}_{4}+4 \mathrm{H}^{+}$ \\
\hline $\begin{array}{l}\text { Wustite } \\
\left(\mathrm{Fe}_{1-\mathrm{x}} \mathrm{O}\right)\end{array}$ & $\mathrm{Fe}^{2+}+\mathrm{O}^{2-} \rightarrow \mathrm{FeO}$ & $\mathrm{Fe}^{2+}+\mathrm{OH}^{-} \rightarrow \mathrm{FeO}+\mathrm{H}^{+}$ \\
\hline Fe substrate & $\mathrm{Fe} \rightarrow \mathrm{Fe}^{2+}+2 \bar{e}$ & $\mathrm{Fe} \rightarrow \mathrm{Fe}^{2+}+2 \bar{e}$ \\
\hline
\end{tabular}
Such anion adsorption is preferred if performed in acidic

Table 1. Oxidation Reactions of Iron in Dry and Water Vapor-Assisted Conditions 


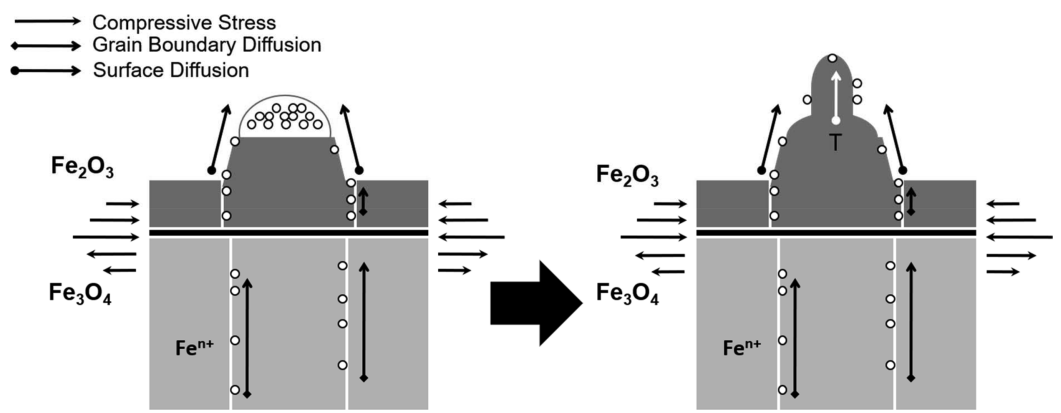

Figure 8. Schematic illustration of the NW growth mechanism through thermal oxidation on an iron foil.
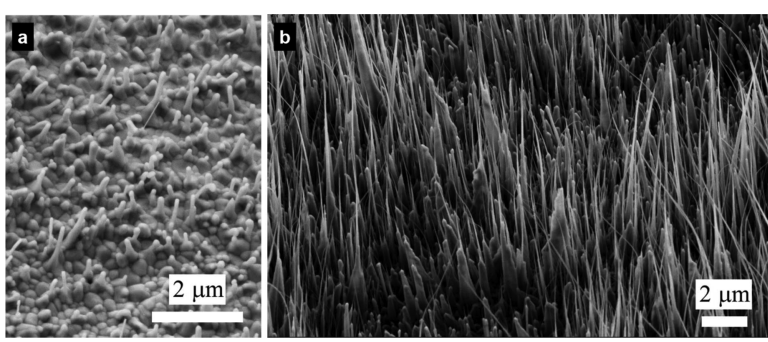

Figure 9. FESEM image showing (a) initial growth of NWs on $\alpha$ $\mathrm{Fe}_{2} \mathrm{O}_{3}$ grains and (b) formation of NWs through surface diffusion.

conditions, as the adsorbent will be protonated due to the existence of $\mathrm{H}^{+}$ions. By considering that the lowest $\mathrm{pH}$ of the chromate ions as the $\mathrm{HCrO}_{4}{ }^{-}$ion is at $\mathrm{pH} 2^{46}$ and the point of zero charge $\left(\mathrm{pH}_{\mathrm{zpc}}\right)$ of $\alpha-\mathrm{Fe}_{2} \mathrm{O}_{3}$ has also been reported to be between $\mathrm{pH} 7.2$ and $\mathrm{pH} \mathrm{9.5,}{ }^{47}$ the condition at $\mathrm{pH} 2$ is reported to be the optimum $\mathrm{pH}$ for effective removal of $\mathrm{Cr}(\mathrm{VI}) .^{48-54}$ Therefore, $\mathrm{pH} 2$ was chosen for the $\mathrm{Cr}(\mathrm{VI})$ adsorption test in this study.

The mechanism of the $\mathrm{Cr}(\mathrm{VI})$ removal is described as follows: Upon the immersion of the $\mathrm{Fe}_{2} \mathrm{O}_{3}$ sample into $\mathrm{Cr}$ (VI) solution, hydroxylation of the surface $(\mathrm{S})$ occurs generating an oxide surface that is covered with hydroxyl ions $\left(\mathrm{OH}^{-}\right)$, forming $\mathrm{S}-\mathrm{OH}$. In acidic $\mathrm{Cr}(\mathrm{VI})$ solution that is rich with $\mathrm{H}^{+}$ ions, sorption of $\mathrm{H}^{+}$(protonation process) then leads to the formation of a positive surface charge at the iron oxidelsolution interface as indicated in eq 8 . The positively charged surface of $\mathrm{Fe}_{2} \mathrm{O}_{3}$ acts as an adsorbent to attract the negatively charged $\mathrm{Cr}(\mathrm{VI})$ species through electrostatic attraction, as shown in eq $9^{55,56}$ and as illustrated in Figure 11a.

$$
\begin{aligned}
& \mathrm{S}-\mathrm{OH}+\mathrm{H}^{+} \rightleftharpoons \mathrm{S}-\mathrm{OH}_{2}^{+} \\
& \mathrm{SOH}_{2}^{+}+\mathrm{HCrO}_{4}^{-} \rightleftharpoons\left(\mathrm{SOH}_{2}^{+}\right) \mathrm{HCrO}_{4}^{-}+\mathrm{H}_{2} \mathrm{O}
\end{aligned}
$$

We also observed precipitates on the oxidized foil as shown in the inset of Figure $11 \mathrm{~b}$. There is a possibility that these precipitates are composed of $\mathrm{Fe}, \mathrm{Cr}(\mathrm{OH})_{3}$ as there is also a possibility of reduction occurring on the surface of the iron oxide. This is in accordance with Richard and Bourg whereby reduction of $\mathrm{Cr}(\mathrm{VI})$ is possible and the formation of $\mathrm{Fe}, \mathrm{Cr}(\mathrm{OH})_{3}$ precipitates can lead to the removal of $\mathrm{Cr}$ (III) completely. ${ }^{57}$ In order to confirm the adsorption of $\mathrm{Cr}$ further, XPS was conducted. Figure $11 \mathrm{~b}$ shows the spectra of $\mathrm{Cr} 2 \mathrm{p}$ with corresponding peaks on $\alpha-\mathrm{Fe}_{2} \mathrm{O}_{3} \mathrm{NWs}$ before and after the $\mathrm{Cr}(\mathrm{VI})$ adsorption process. The spectrum indicated the presence of $\mathrm{Cr}$ on the $\alpha-\mathrm{Fe}_{2} \mathrm{O}_{3} \mathrm{NWs}$, at 585 and $575 \mathrm{eV}$ after the adsorption process. The peaks correspond to the binding energies of $\operatorname{Cr} 2 \mathrm{p}_{1 / 2}$ and $\operatorname{Cr} 2 \mathrm{p}_{3 / 2}$, respectively.

Although the protonation of iron oxide is necessary for adsorption of the negatively charged $\mathrm{Cr}(\mathrm{VI})$ adsorption, this process also triggers Fe dissolution to occur. ${ }^{15}$ The dissolution reaction is initiated by single-proton adsorption at a neutral surface $\mathrm{OH} / \mathrm{OH}_{2}$ pair, thus converting it into $\mathrm{Fe}\left(\mathrm{OH}_{2}\right)^{2+}$. Then, continuous adsorption of two protons at the same time would weaken the $\mathrm{Fe}-\mathrm{O}$ bond, causing the dissolution of $\mathrm{Fe}$ from the oxide surface. However, this dissolution step is ratelimiting, as the activation energy is higher for dissolution to occur, compared to the protonation process. ${ }^{15}$ Therefore in our case, the dissolved Fe ions further reacted with $\mathrm{Cr}(\mathrm{VI})$ species, reducing them to $\mathrm{Cr}$ (III) followed by precipitation. This indicates that there could be (minor) iron oxide
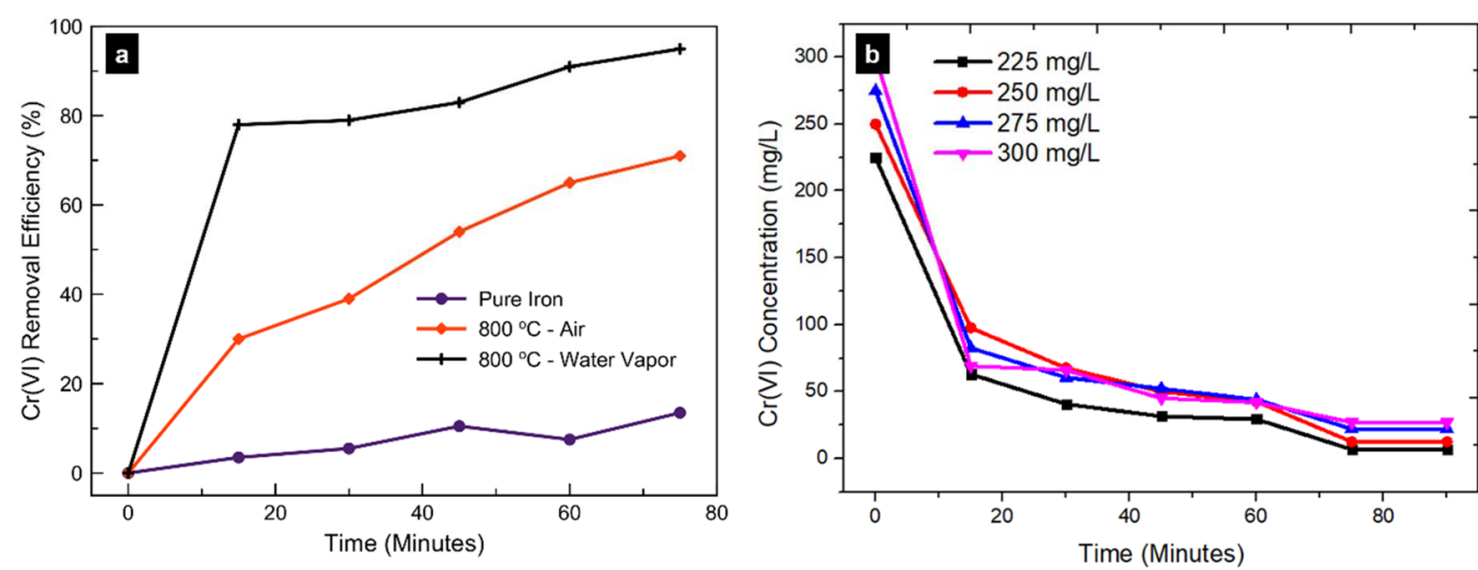

Figure 10. $\mathrm{Cr}(\mathrm{VI})$ adsorption profiles from $\mathrm{Cr}(\mathrm{VI})$ solution: (a) using the $\alpha$ - $\mathrm{Fe}_{2} \mathrm{O}_{3} \mathrm{NW}$ samples synthesized at $800{ }^{\circ} \mathrm{C}$ in air and water vapor and (b) varying concentrations between 225 and $300 \mathrm{mg} / \mathrm{L}$ using $\alpha-\mathrm{Fe}_{2} \mathrm{O}_{3} \mathrm{NWs}$ obtained from thermal oxidation at $800{ }^{\circ} \mathrm{C}$ in water vapor. 

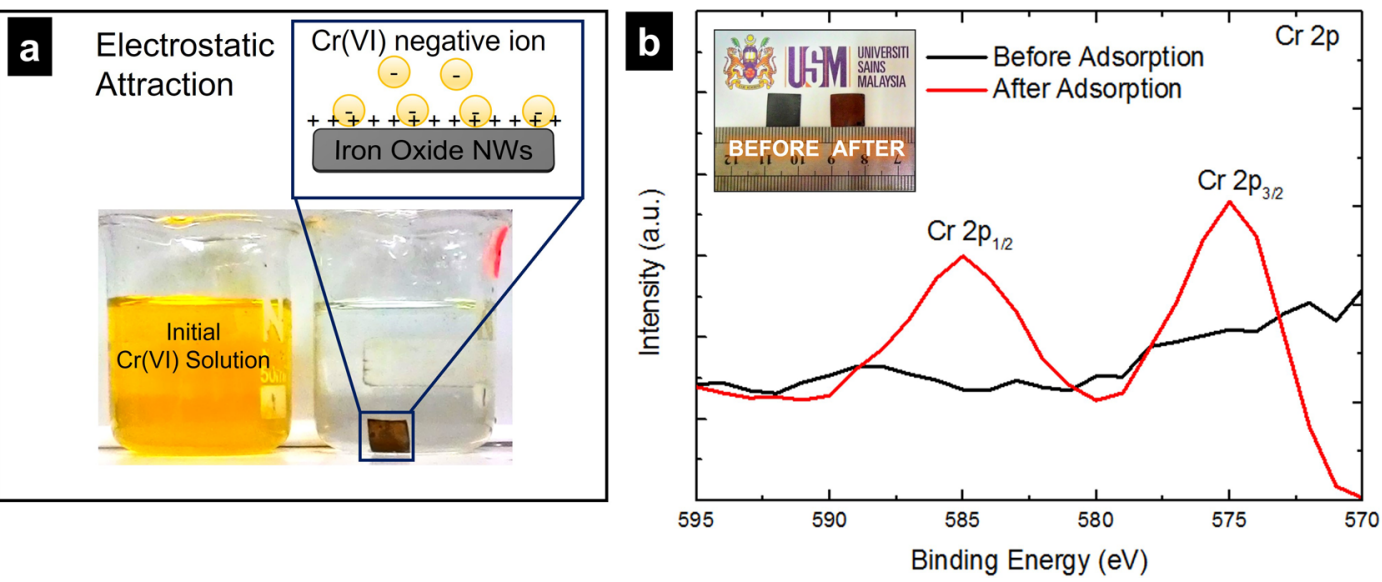

Figure 11. (a) Photograph showing the solution before and after the $\mathrm{Cr}(\mathrm{VI})$ adsorption process with an illustration of the surface adsorption mechanism (inset) and (b) XPS spectra of Cr $2 \mathrm{p}$ of the $\alpha-\mathrm{Fe}_{2} \mathrm{O}_{3} \mathrm{NWs}$ (before and after the $\mathrm{Cr}$ (VI) adsorption process).
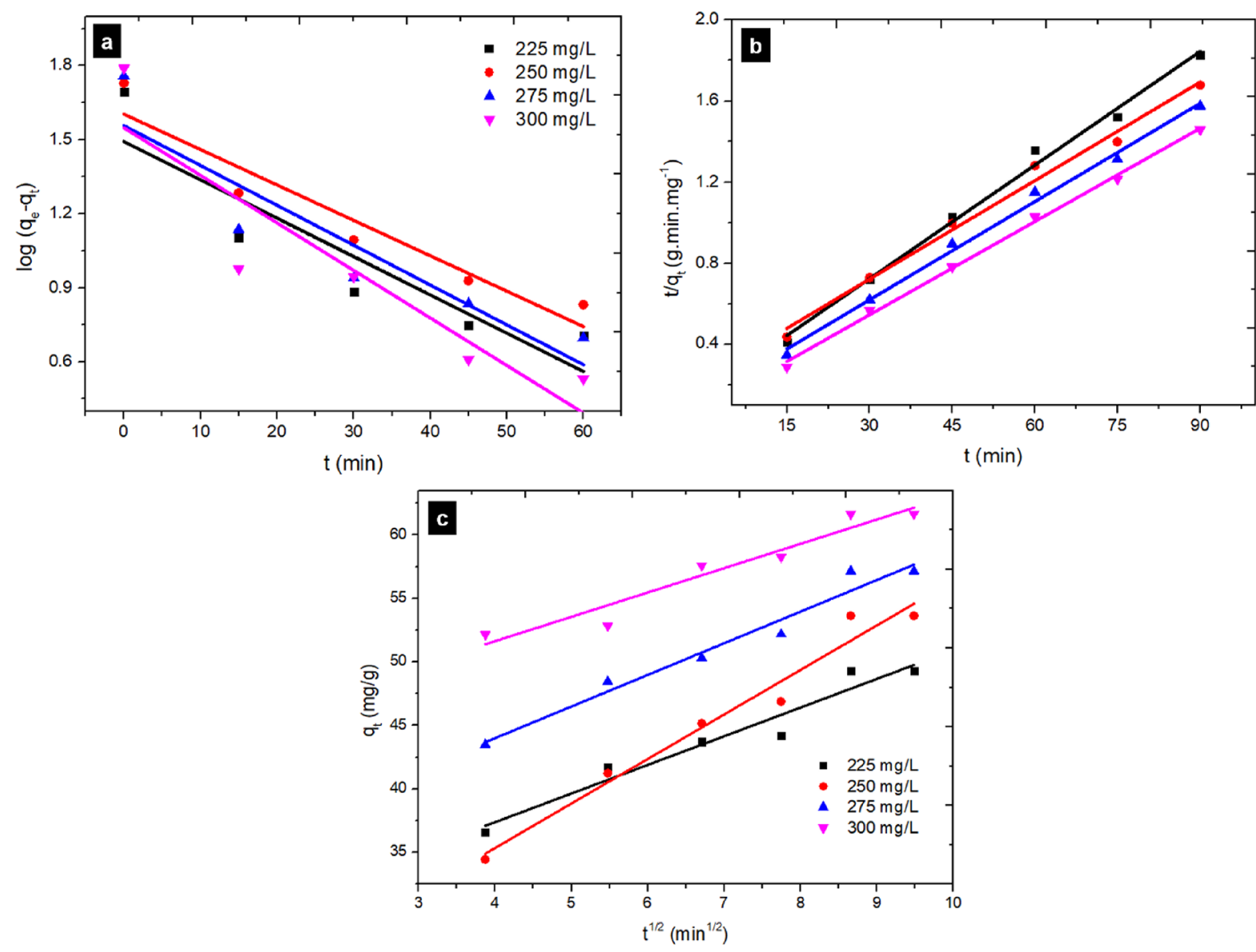

Figure 12. Linear fit of $\alpha-\mathrm{Fe}_{2} \mathrm{O}_{3} \mathrm{NW}$ kinetics to (a) pseudo-first-order kinetic, (b) pseudo-second-order kinetic, and (c) intraparticle diffusion models.

dissolution in acidic solution. Therefore, we deduce that our sample is more suitable to be used for single removal use. However, in terms of reproducibility, the $\mathrm{Cr}(\mathrm{VI})$ removal results shown in Figure $10 \mathrm{~b}$ indicated a rather consistent removal property.

2.5. Determination of Adsorption Kinetics. Kinetic adsorption describes the rate of the adsorption process by monitoring the change of adsorbate concentration against time; thus, the dynamic movement of the adsorbate to the adsorbent can be predicted. By knowing the rate of adsorption, we were able to investigate an appropriate kinetic model by fitting the data to several kinetic adsorption models: (1) pseudo-first-order, (2) pseudo-second-order, and (3) intraparticle diffusion, which are illustrated in Figure 12. The validity of the predicted models with the experimental data was determined using values of $R^{2}$, which are presented in Table 2 along with the corresponding correlation coefficients; the closer the value of $R^{2}$ to 1 , the better the model fitted the adsorption kinetics of $\mathrm{Cr}(\mathrm{VI})$ in the tested system. The details of the fitting of each model are described below. 
Table 2. Comparison of the Kinetic Models Fitted for Cr(VI) Adsorption

\begin{tabular}{cccc} 
method & sample & $R^{2}$ & kinetic rate constant \\
pseudo-first order & $225 \mathrm{mg} / \mathrm{L}$ & 0.77800 & $k_{1}=0.03576$ \\
& $250 \mathrm{mg} / \mathrm{L}$ & 0.88960 & $k_{1}=0.03304$ \\
& $275 \mathrm{mg} / \mathrm{L}$ & 0.80328 & $k_{1}=0.03719$ \\
& $300 \mathrm{mg} / \mathrm{L}$ & 0.78220 & $k_{1}=0.00443$ \\
\hline pseudo-second order & $225 \mathrm{mg} / \mathrm{L}$ & 0.99159 & $k_{2}=0.00214$ \\
& $250 \mathrm{mg} / \mathrm{L}$ & 0.98664 & $k_{2}=0.00111$ \\
& $275 \mathrm{mg} / \mathrm{L}$ & 0.99300 & $k_{2}=0.00194$ \\
& $300 \mathrm{mg} / \mathrm{L}$ & 0.99692 & $k_{2}=0.00027$ \\
\hline intraparticle diffusion & $225 \mathrm{mg} / \mathrm{L}$ & 0.93541 & $k_{\text {id }}=2.25689$ \\
& $250 \mathrm{mg} / \mathrm{L}$ & 0.91151 & $k_{\text {id }}=3.50526$ \\
& $275 \mathrm{mg} / \mathrm{L}$ & 0.92915 & $k_{\text {id }}=2.49014$ \\
& $300 \mathrm{mg} / \mathrm{L}$ & 0.91090 & $k_{\text {id }}=1.91565$ \\
\hline
\end{tabular}

2.5.1. Pseudo-First-Order Kinetic Model. The linear fit of $\mathrm{Cr}(\mathrm{VI})$ adsorption on $\alpha-\mathrm{Fe}_{2} \mathrm{O}_{3} \mathrm{NWs}$ in accordance with a pseudo-first-order kinetic model is presented in Figure 12a. The pseudo-first-order model follows an adsorption process according to eq $10^{58}$

$$
\frac{\mathrm{d} q_{t}}{\mathrm{~d} t}=k\left(q_{\mathrm{e}}-q_{t}\right)
$$

By applying the initial condition, $q_{t}=0$ at $t=0$ and $q_{t}=q_{t}$ at $t$ $=t$, the integration of the pseudo-first-order model can be expressed as eq 11

$$
\log \left(q_{\mathrm{e}}-q_{t}\right)=\log q_{\mathrm{e}}-0.434 k_{\mathrm{l}} t
$$

where $q_{\mathrm{e}}$ and $q_{t}$ are the total adsorbed $\mathrm{Cr}(\mathrm{VI})$ at equilibrium and at time $t\left(\mathrm{mg} \mathrm{g}^{-1}\right)$, respectively, and $k_{1}$ is the pseudo-firstorder kinetic constant $\left(\mathrm{min}^{-1}\right)$. The $R^{2}$ values for the pseudofirst-order kinetic model in Table 2 are below 0.8, indicating that the experimental data deviated from the theoretical data; therefore, this model was unsuitable.

2.5.2. Pseudo-Second-Order Kinetic Model. The linear fit of $\mathrm{Cr}(\mathrm{VI})$ adsorption on $\alpha-\mathrm{Fe}_{2} \mathrm{O}_{3}$ NWs according to the pseudo-second-order kinetic model is presented in Figure 12b. The pseudo-second-order kinetic model follows an adsorption process according to eq 12 , which describes a kinetic rate driven by chemisorption ${ }^{58}$

$$
\frac{\mathrm{d} q_{t}}{\mathrm{~d} t}=k_{2}\left(q_{\mathrm{e}}-q_{t}\right)^{2}
$$

By applying the initial condition, $q_{t}=0$ at $t=0$ and $q_{t}=q_{t}$ at $t=t$, the integration of the pseudo-second-order kinetic model can be expressed by eq 13

$$
\frac{t}{q_{t}}=\frac{1}{k_{2} q_{\mathrm{e}}{ }^{2}}+\frac{1}{q_{\mathrm{e}}} t
$$

where $q_{\mathrm{e}}$ and $q_{t}$ are the total adsorbed chromium at equilibrium and at time $t\left(\mathrm{mg} \mathrm{g}^{-1}\right)$, respectively. The value of $k_{2}$ is the rate constant of pseudo-second-order adsorption $\left(\mathrm{g} \mathrm{mg}^{-1} \mathrm{~min}^{-1}\right)$. The $R^{2}$ values obtained for all the concentrations investigated were higher than 0.98 for the pseudo-second-order model, as shown in Table 2, indicating that it is appropriate to describe the dynamic behavior of $\mathrm{Cr}(\mathrm{VI})$ adsorption onto $\alpha-\mathrm{Fe}_{2} \mathrm{O}_{3}$ NWs.

2.5.3. Intraparticle Diffusion Model. The linear fit of $\mathrm{Cr}(\mathrm{VI})$ adsorption on $\alpha-\mathrm{Fe}_{2} \mathrm{O}_{3}$ NWs according to the intraparticle diffusion model is presented in Figure 12c. The intraparticle diffusion model describes an adsorption process that occurs in multiple stages. ${ }^{58}$ First, a sharp $\mathrm{Cr}$ (VI) concentration reduction indicates a spontaneous adsorption process. Second, a gradual adsorption is driven by a controlled diffusion phenomenon. Finally, the low concentration of the remaining adsorbate results in a slow adsorption process. The intraparticle diffusion model can be expressed using eq 14

$$
q_{t}=k_{\mathrm{id}}(t)^{1 / 2}+c
$$

where $q_{t}\left(\mathrm{mg} \mathrm{g}^{-1}\right)$ is the amount of $\mathrm{Cr}(\mathrm{VI})$ adsorbed, $k_{\mathrm{id}}$ is the rate factor $\left(\mathrm{mg} / \mathrm{g} / \mathrm{min}^{1 / 2}\right)$, and $c\left(\mathrm{mg} \mathrm{g}^{-1}\right)$ represents the boundary layer thickness. The $R^{2}$ values for the intraparticle diffusion model, presented in Table 2 , are close to 0.9 , which are even lower than the values obtained for the pseudo-secondorder kinetic model. This indicated that the intraparticle diffusion model was unsuitable.

2.6. Investigation on the Adsorption Equilibrium. To determine the loading capacity of the adsorbent, we continued investigating the equilibrium. The adsorption data were fitted to the Langmuir and Freundlich models, and the obtained plots are presented in Figure 13. Similarly, in the kinetic study, the validity was determined by $R^{2}$ values, i.e., the closer the $R^{2}$
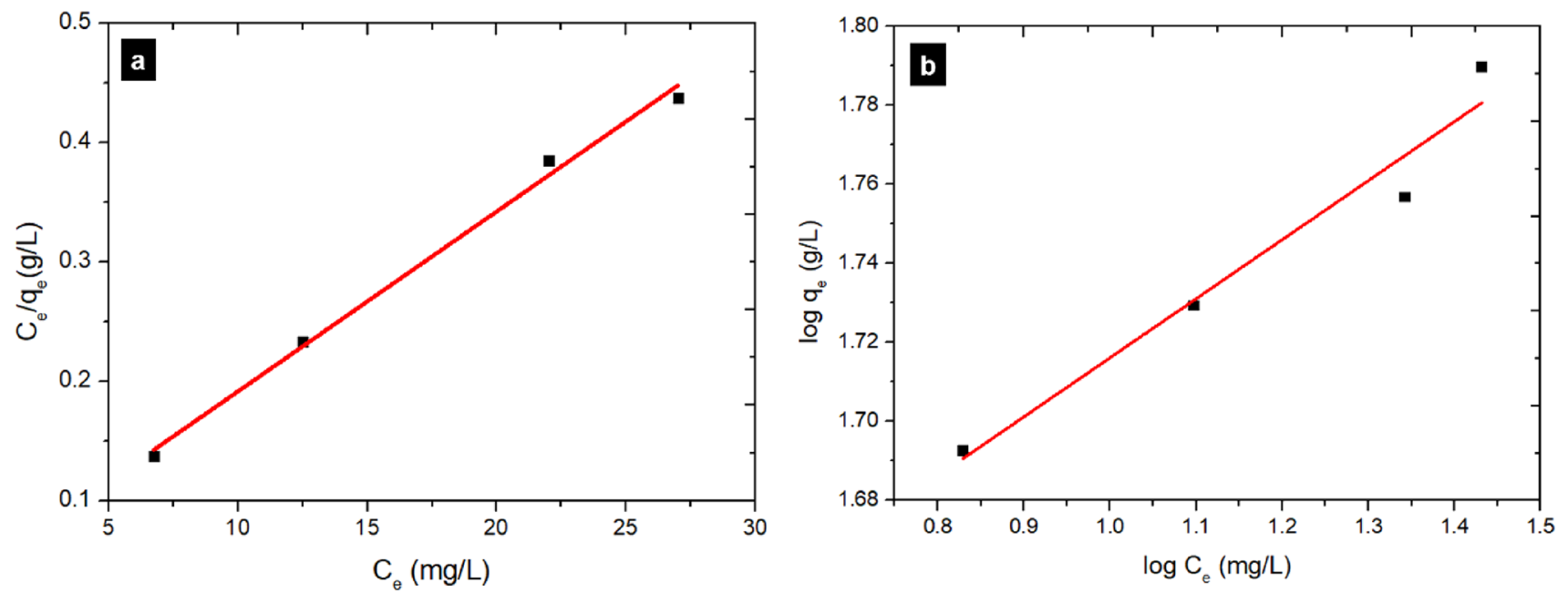

Figure 13. Linear fit of $\mathrm{Cr}(\mathrm{VI})$ adsorption equilibrium to (a) Langmuir and (b) Freundlich models. 
was to 1 , the better the fit of the model was. The correlation coefficient and the $R^{2}$ value for each model are presented in Table 3. Each model is described below.

Table 3. Summary of the Adsorption Equilibrium Modeling

\begin{tabular}{cccccccc}
\multicolumn{3}{c}{ Langmuir } & & \multicolumn{3}{c}{ Freundlich } \\
\cline { 1 - 3 } \cline { 5 - 7 }$q_{\mathrm{m}}(\mathrm{mg} / \mathrm{g})$ & $K_{\mathrm{L}}$ & $R^{2}$ & & $n$ & $K_{\mathrm{F}}$ & $R^{2}$ \\
6 & 0.37690 & 0.37048 & 0.99209 & & 6.68851 & 36.86888 & 0.94082 \\
\hline
\end{tabular}

2.6.1. Langmuir Model. The linear fit of $\mathrm{Cr}(\mathrm{VI})$ adsorption on $\alpha-\mathrm{Fe}_{2} \mathrm{O}_{3}$ NWs according to the Langmuir model is presented in Figure 13a. The Langmuir model describes an adsorption process that occurs across a homogeneous adsorbent surface, ${ }^{59}$ which can be described by eq 15

$$
\frac{C_{\mathrm{e}}}{q_{\mathrm{e}}}=\frac{1}{K_{\mathrm{L}} \cdot q_{\mathrm{m}}}+\frac{1}{q_{\mathrm{m}}} \cdot C_{\mathrm{e}}
$$

where $K_{\mathrm{L}}\left(\mathrm{L} \mathrm{mg}^{-1}\right)$ is the Langmuir equilibrium constant and $q_{\mathrm{m}}\left(\mathrm{mg} \mathrm{g}^{-1}\right)$ is the monolayer capacity, which indicates the available active sites per mass of the sample where $\mathrm{Cr}(\mathrm{VI})$ could be adsorbed. The $R^{2}$ value for the Langmuir model was close to 0.99 , indicating that it fitted the equilibrium behavior of $\mathrm{Cr}(\mathrm{VI})$ adsorption onto $\alpha-\mathrm{Fe}_{2} \mathrm{O}_{3} \mathrm{NWs}$ well. The calculated adsorption capacity of $\alpha-\mathrm{Fe}_{2} \mathrm{O}_{3}$ NWs for $\mathrm{Cr}(\mathrm{VI})$ using the Langmuir model was approximately $66.2690 \mathrm{mg} / \mathrm{g}$.

2.6.2. Freundlich Model. The linear fit of $\mathrm{Cr}(\mathrm{VI})$ adsorption on $\alpha-\mathrm{Fe}_{2} \mathrm{O}_{3} \mathrm{NWs}$ according to the Freundlich model is presented in Figure 13b. The Freundlich model describes an adsorption process that occurs across a heterogeneous adsorbent surface, ${ }^{59}$ which can be described by eq 16

$$
\log q_{\mathrm{e}}=\log K_{\mathrm{F}}+\frac{1}{n} \cdot \log C_{\mathrm{e}}
$$

where $K_{\mathrm{F}}\left(\mathrm{mg} \mathrm{g}^{-1}\right)$ is the Freundlich constant, which describes the adsorption capacity, and $1 / n$ is the heterogeneity factor. It can be seen from Table 3 that the $R^{2}$ value for the Freundlich model was below 0.95 , indicating that the experimental data deviated from the theoretical data; therefore, the Freundlich model was unsuitable.

Finally, to demonstrate the impact of our findings, we compiled and compared previously reported $\mathrm{Cr}$ (VI) adsorption properties of iron oxide, presented in Table 4. This demonstrated that iron oxides can be used for $\mathrm{Cr}(\mathrm{VI})$ adsorption but that their adsorption properties differ depending on their morphologies. As previously mentioned, the

Table 4. Iron Oxide $\mathrm{Cr}(\mathrm{VI})$ Adsorption Values from This Study and the Literature

\begin{tabular}{lcccc}
\multicolumn{1}{c}{$\begin{array}{c}\text { iron oxide adsorbent } \\
\text { material }\end{array}$} & $\mathrm{pH}$ & $\begin{array}{c}\mathrm{T} \\
\left({ }^{\circ} \mathrm{C}\right)\end{array}$ & $\begin{array}{c}\text { adsorption capacity } \\
(\mathrm{mg} / \mathrm{g})\end{array}$ & references \\
\hline maghemite nanoparticles & 2.5 & 25 & 19.2 & 49 \\
$3 \mathrm{D}$ hierarchical $\alpha$ - $\mathrm{Fe}_{2} \mathrm{O}_{3}$ & 3.0 & 25 & 34.4 & 50 \\
$\alpha$ - $\mathrm{Fe}_{2} \mathrm{O}_{3}$ nanofibers & 3.0 & 25 & 16.17 & 26 \\
$\alpha-\mathrm{Fe}_{2} \mathrm{O}_{3}$ nanoparticles & 3.0 & 25 & 200 & 48 \\
$\alpha$ - $\mathrm{Fe}_{2} \mathrm{O}_{3}$ nanofibers & 6.0 & 25 & 90.9 & 55 \\
$\mathrm{Fe}^{3+}$ oxide/hydroxide NP & 4.0 & 25 & 31.5 & 51 \\
flower-like $\alpha$ - $\mathrm{Fe}_{2} \mathrm{O}_{3}$ & 3.0 & 25 & 7.6 & 52 \\
nanocrystalline iron oxide & 2.0 & 25 & 2.29 & 53 \\
$\alpha$ - $\mathrm{Fe}_{2} \mathrm{O}_{3}$ nanostructure & 2.0 & 25 & 22.72 & 54 \\
$\alpha$ - $\mathrm{Fe}_{2} \mathrm{O}_{3}$ nanowires & 2.0 & 25 & 66.26 & this study
\end{tabular}

adsorption capacity of $\mathrm{Cr}(\mathrm{VI})$ onto iron oxide is influenced by the $\mathrm{pH}$ of the solution, with a low $\mathrm{pH}$ being preferable to promote a higher adsorption capacity. ${ }^{48}$ Another factor that affects $\mathrm{Cr}(\mathrm{VI})$ adsorption is the specific surface area that is available for adsorption. Nalbandian et al. achieved an improved adsorption capacity of $90.9 \mathrm{mg} / \mathrm{g}$ using smalldiameter (i.e., higher surface area) $\alpha-\mathrm{Fe}_{2} \mathrm{O}_{3}$ nanofibers. ${ }^{55}$ The TEM and SEM images in Figures 2 and 4 allowed us to estimate the surface area provided by one NW to be approximately $204.28 \times 10^{-15} \mathrm{~m}^{2}$. On a $1 \mathrm{~cm} \times 1 \mathrm{~cm}$ oxidized iron foil, we estimated there to be approximately $3 \times 10^{10} \mathrm{NWs}$ on the surface, assuming a homogeneous distribution; therefore, we consider our $\mathrm{Cr}(\mathrm{VI})$ adsorption capacity of $66.26 \mathrm{mg} / \mathrm{g}$ to be rather good. Although this is lower than the $90.9 \mathrm{mg} / \mathrm{g}$ values reported by Nalbandian et al., ${ }^{55}$ the use of $\alpha$ $\mathrm{Fe}_{2} \mathrm{O}_{3}$ NWs on iron foils enables their simple removal from the target solution. This indicates that the formation of $\alpha-\mathrm{Fe}_{2} \mathrm{O}_{3}$ NWs by the water vapor-assisted surface oxidation of iron has an excellent potential for the removal of harmful $\mathrm{Cr}(\mathrm{VI})$ from wastewater.

\section{CONCLUSIONS}

We investigated the high-temperature $\left(700\right.$ and $800{ }^{\circ} \mathrm{C}$ ) formation of iron oxide nanostructures through thermal oxidation in dry-air- and water vapor-assisted conditions. Oxidation at $700{ }^{\circ} \mathrm{C}$ led to the formation of coral-like nanostructures, whereas $\alpha$ - $\mathrm{Fe}_{2} \mathrm{O}_{3} \mathrm{NWs}$ were obtained from oxidation at $800{ }^{\circ} \mathrm{C}$. Water vapor-assisted thermal oxidation resulted in an increased rate of oxide formation and larger or denser coral-like or NW structures with high aspect ratios at 700 and $800{ }^{\circ} \mathrm{C}$, respectively. Through systematically observing the oxidation process, we were able to describe the formation mechanism of the $\alpha-\mathrm{Fe}_{2} \mathrm{O}_{3}$ NWs, which was a stressdriven mechanism through surface diffusion. Notably, NWs were produced after $5 \mathrm{~min}$ of oxidation, but the densest NWs with the highest aspect ratios were obtained only after 120 min. We then evaluated the $\mathrm{Cr}(\mathrm{VI})$ adsorption property of $\alpha$ $\mathrm{Fe}_{2} \mathrm{O}_{3}$ NWs obtained from water vapor-assisted thermal oxidation at $800{ }^{\circ} \mathrm{C}$ for $2 \mathrm{~h}$. A removal efficiency of $97 \%$ was achieved within 90 min using an aqueous $\mathrm{Cr}(\mathrm{VI})$ solution with a concentration of $225 \mathrm{mg} / \mathrm{L}$. Finally, we investigated the adsorption equilibrium and kinetic models, which agreed with the Langmuir and pseudo-second-order kinetic models, respectively. The adsorption capacity of these $\alpha-\mathrm{Fe}_{2} \mathrm{O}_{3} \mathrm{NWs}$ was calculated to be $66.26 \mathrm{mg} / \mathrm{g}$. This simple methodology for forming high-aspect-ratio $\alpha-\mathrm{Fe}_{2} \mathrm{O}_{3} \mathrm{NWs}$ through surface oxidation has a great potential for producing large-surfacearea adsorbents to enable the simple removal of $\mathrm{Cr}$ ions from aqueous systems. The findings of this study will be beneficial and useful for the removal and mitigation of harmful $\mathrm{Cr}$ (VI) ions from wastewater.

\section{EXPERIMENTAL PROCEDURES}

The $1 \times 1 \mathrm{~cm}$ iron foils (99.9\%, Nilaco Corporation) were polished with a 2000 grit silicon carbide paper, ultrasonically cleaned in acetone, rinsed using deionized water, and then dried. Then, they were placed in an alumina crucible and positioned in the hot zone of a horizontal furnace. The furnace was progressively heated by $5{ }^{\circ} \mathrm{C} / \mathrm{min}$ until the desired oxidation temperature was reached, which was either 700 or $800{ }^{\circ} \mathrm{C}$. Once this temperature was reached, the furnace was purged with water vapor generated using a nebulizer (Omron 
NE-C801). The evolution of the surface oxide was monitored using a field-emission electron microscope (FESEM) (Zeiss Supra $35 \mathrm{VP}$ ), and higher-magnification images were obtained using a high-resolution transmission electron microscope (HRTEM) (Tecnai $G^{2} 20$ S-TWIN). Crystal structures were examined by taking X-ray diffraction (XRD) patterns (Bruker D8 Advance diffractometer) with a $\mathrm{Cu} \mathrm{K} \alpha$ radiation source $(\lambda$ $=0.154 \mathrm{~nm}$ ) A Raman spectrometer (Renishaw RL633) was used for phase identification, and an X-ray photoelectron spectrophotometer (XPS) (Kratos Axis Ultra XPS Spectroscopy) with an $\mathrm{Al} \mathrm{X}$-ray radiation source was used for surface and elemental analysis.

To evaluate the $\mathrm{Cr}(\mathrm{VI})$ removal ability of the nanostructures, oxidized iron with $\alpha-\mathrm{Fe}_{2} \mathrm{O}_{3} \mathrm{NWs}$ was placed in $\mathrm{Cr}(\mathrm{VI})$ solutions of various concentrations between 225 and $300 \mathrm{mg} /$ $\mathrm{L}$, at room temperature. The $\mathrm{pH}$ of the solutions was adjusted to $\mathrm{pH} 2$ by adding $\mathrm{H}_{2} \mathrm{SO}_{4}(27 \%)$. The assessment of the $\mathrm{Cr}(\mathrm{VI})$ content was performed using a diphenyl-carbazide (DPC) colorimetry method. DPC solution was prepared by diluting $0.25 \mathrm{~g}$ of 1,5-diphenylcarbazide in $50 \mathrm{~mL}$ of acetone, and a droplet was added into the $\mathrm{Cr}(\mathrm{VI})$ solutions. A color change in the solution to purple indicated the existence of $\mathrm{Cr}$ (VI). UV-visible (UV-vis) measurements were taken with a UV-vis spectrophotometer (PerkinElmer Lambda 35), and absorption values were recorded at a wavelength of $540 \mathrm{~nm}$ to detect $\mathrm{Cr}$ (VI). ${ }^{37}$ The adsorption study was divided into two parts: equilibrium and kinetic. First, $50 \mathrm{~mL}$ solutions of $\mathrm{Cr}(\mathrm{VI})$ with concentrations ranging from 225 to $300 \mathrm{mg} / \mathrm{L}$ were prepared. The $\alpha-\mathrm{Fe}_{2} \mathrm{O}_{3} \mathrm{NWs}$ were then immersed in the $\mathrm{Cr}(\mathrm{VI})$ solution. During this adsorption process, bubbles, which were supplied by an air pump (Super X Classica) with an output of $250 \mathrm{~L} / \mathrm{h}$, were used for stirring the $\mathrm{Cr}(\mathrm{VI})$ solution. The amount of $\mathrm{Cr}(\mathrm{VI})$ adsorbed at the equilibrium condition $\left(q_{\mathrm{e}}\right)$ was calculated using eq 17

$$
q_{\mathrm{e}}=\frac{\left(C_{\mathrm{o}}-C_{\mathrm{e}}\right) \cdot V}{m}
$$

where $C_{\mathrm{o}}$ and $C_{\mathrm{e}}$ are the initial and equilibrium concentrations of $\mathrm{Cr}(\mathrm{VI})(\mathrm{mg} / \mathrm{L})$, respectively, $V$ is the volume of solution used $(\mathrm{L})$, and $m$ is the mass of the adsorbent $(\mathrm{g})$. For the kinetic study, the amount of $\mathrm{Cr}(\mathrm{VI})$ adsorbed at time $t\left(q_{t}\right)$ was calculated using eq 18

$$
q_{t}=\frac{\left(C_{\mathrm{o}}-C_{t}\right) \cdot V}{m}
$$

where $C_{t}$ is the concentration of $\mathrm{Cr}(\mathrm{VI})$ at time $t$.

\section{AUTHOR INFORMATION}

\section{Corresponding Authors}

Wai Kian Tan - Institute of Liberal Arts \& Sciences,

Toyohashi University of Technology, Toyohashi, Aichi 4418580, Japan; 이 orcid.org/0000-0002-0014-5475;

Email: tan@las.tut.ac.jp

Zainovia Lockman - Green Electronic Nanomaterials Group, School of Materials and Mineral Resources Engineering, Engineering Campus, Universiti Sains Malaysia, Nibong

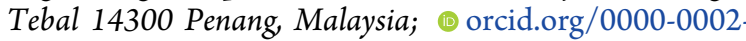
1535-8035; Email: zainovia@usm.my

\section{Authors}

Faisal Budiman - Green Electronic Nanomaterials Group, School of Materials and Mineral Resources Engineering, Engineering Campus, Universiti Sains Malaysia, Nibong
Tebal 14300 Penang, Malaysia; Department of Electrical Engineering, School of Electrical Engineering, Telkom University, Bandung 40257, Indonesia

Go Kawamura - Department of Electrical and Electronic Information Engineering, Toyohashi University of Technology, Toyohashi, Aichi 441-8580, Japan; (1) orcid.org/0000-0001-6585-7636

Hiroyuki Muto - Institute of Liberal Arts \& Sciences and Department of Electrical and Electronic Information Engineering, Toyohashi University of Technology, Toyohashi, Aichi 441-8580, Japan

Atsunori Matsuda - Department of Electrical and Electronic Information Engineering, Toyohashi University of Technology, Toyohashi, Aichi 441-8580, Japan; (1) orcid.org/0000-0002-6493-1205

Khairunisak Abdul Razak - Green Electronic Nanomaterials Group, School of Materials and Mineral Resources Engineering, Engineering Campus, Universiti Sains Malaysia, Nibong Tebal 14300 Penang, Malaysia; ㅇo․ orid.org/00000003-0140-2418

Complete contact information is available at: https://pubs.acs.org/10.1021/acsomega.1c04280

\section{Notes}

The authors declare no competing financial interest.

\section{ACKNOWLEDGMENTS}

Z.L. acknowledges the USM Research University Grant from the Toyohashi University of Technology, the Japan-USM Collaboration (1001/PBAHAN/870048) for Heavy Metal Mitigation, and the AUN-SEED/Net JICA through the Collaborative Research (CR) Grant for F.B. F.B. acknowledges the Ministry of Education of Indonesia for providing the grant for fine-tuning activities for this joint publication through the 2021 World Class Professor Program. A.M., G.K., and W.K.T. acknowledge the JSPS KAKENHI (grant numbers 18H03841, $21 \mathrm{~K} 18823$, and $18 \mathrm{~K} 14013)$ for supporting this research.

\section{REFERENCES}

(1) Guertin, J.; Avakian, C. P; Jacobs, J. A. Chromium (VI) handbook; CRC Press: Florida, 2016.

(2) Rahman, Z.; Singh, V. P. The relative impact of toxic heavy metals (THMs) (arsenic (As), cadmium (Cd), chromium (Cr)(VI), mercury $(\mathrm{Hg})$, and lead $(\mathrm{Pb}))$ on the total environment: an overview. Environ. Monit. Assess. 2019, 191, 419.

(3) Lin, C.-H.; Lai, C.-H.; Peng, Y.-P.; Wu, P.-C.; Chuang, K.-Y.; Yen, T.-Y.; Xiang, Y.-K. Comparative health risk of inhaled exposure to organic solvents, toxic metals, and hexavalent chromium from the use of spray paints in Taiwan. Environ. Sci. Pollut. Res. 2019, 26, 33906-33916.

(4) Lejding, T.; Engfeldt, M.; Bruze, M.; Isaksson, M.; Svedman, C.; Zimerson, E.; Verma, K.; Mowitz, M. Skin application of glutathione and iron sulfate can inhibit elicitation of allergic contact dermatitis from hexavalent chromium. Contact Dermatitis 2019, 82, 45-53.

(5) Yu, J.-H.; Lu, J.-X.; Smollin, C.; Cheng, H.-T.; Seak, C.-J.; Chen, H.-Y. N-acetylcysteine and ascorbic acid therapy for acute hepatic injury after hexavalent chromium ingestion. J. Clin. Pharm. Ther. 2020, 45, 208-210.

(6) Rosli, S.-A.; Alias, N.; Bashirom, N.; Ismail, S.; Tan, W.-K.; Kawamura, G.; Matsuda, A.; Lockman, Z. Hexavalent Chromium Removal via Photoreduction by Sunlight on Titanium-Dioxide Nanotubes Formed by Anodization with a Fluorinated GlycerolWater Electrolyte. Catalysts 2021, 11, 376.

(7) WHO Guidelines for drinking-water quality; World Health Organization: Geneva, 2011. 
(8) Gao, Z.; Yang, H.; Fu, X.; Jin, Q.; Wu, Q.; Kang, L.; Wu, J. Efficient photoreduction of $\mathrm{Cr}(\mathrm{VI})$ on $\mathrm{TiO}_{2} /$ functionalized activated carbon $\left(\mathrm{TiO}_{2} / \mathrm{AC}\right.$-AEMP): improved adsorption of $\mathrm{Cr}(\mathrm{VI})$ and induced transfer of electrons. Environ. Sci. Pollut. Res. 2020, 27, 17446-17457.

(9) Bashirom, N.; Tan, W.-K.; Kawamura, G.; Matsuda, A.; Lockman, Z. Comparison of $\mathrm{ZrO}_{2}, \mathrm{TiO}_{2}$, and $\alpha-\mathrm{Fe}_{2} \mathrm{O}_{3}$ nanotube arrays on $\mathrm{Cr}(\mathrm{VI})$ photoreduction fabricated by anodization of $\mathrm{Zr}, \mathrm{Ti}$, and Fe foils. Mater. Res. Express 2020, 7, No. 055013.

(10) Hu, B.; Ai, Y.; Jin, J.; Hayat, T.; Alsaedi, A.; Zhuang, L.; Wang, $\mathrm{X}$. Efficient elimination of organic and inorganic pollutants by biochar and biochar-based materials. Biochar 2020, 2, 47-64.

(11) Xie, B.; Shan, C.; Xu, Z.; Li, X.; Zhang, X.; Chen, J.; Pan, B. One-step removal of $\mathrm{Cr}(\mathrm{VI})$ at alkaline $\mathrm{pH}$ by $\mathrm{UV} /$ sulfite process: reduction to $\mathrm{Cr}$ (III) and in situ Cr (III) precipitation. Chem. Eng. J. 2017, 308, 791-797.

(12) Zheng, Y.; Yan, Y.; Yu, L.; Li, H.; Jiao, B.; Shiau, Y.; Li, D. Synergism of citric acid and zero-valent iron on $\mathrm{Cr}$ (VI) removal from real contaminated soil by electrokinetic remediation. Environ. Sci. Pollut. Res. 2020, 27, 5572-5583.

(13) Abdullah, N.; Yusof, N.; Shah, M. H. A.; Ikhsan, S.-N.-W.; Ng, Z.-C.; Maji, S.; Lau, W.-J.; Jaafar, J.; Ismail, A.-F.; Ariga, K. Hydrous ferric oxide nanoparticles hosted porous polyethersulfone adsorptive membrane: chromium (VI) adsorptive studies and its applicability for water/wastewater treatment. Environ. Sci. Pollut. Res. 2019, 26, 20386-20399.

(14) Hu, B.; Wang, H.; Liu, R.; Qiu, M. Highly efficient U (VI) capture by amidoxime/carbon nitride composites: Evidence of EXAFS and modeling. Chemosphere 2021, 274, 129743.

(15) Zhang, R.; Zeng, Q.; Guo, P.; Cui, Y.; Sun, Y. Efficient capture of $\mathrm{Cr}$ (VI) by carbon hollow fibers with window-like structure. Environ. Sci. Pollut. Res. 2020, 27, 16763-16773.

(16) Liu, X.; Pang, H.; Liu, X.; Li, Q.; Zhang, N.; Mao, L.; Qiu, M.; $\mathrm{Hu}$, B.; Yang, H.; Wang, X. Orderly porous covalent organic frameworks-based materials: superior adsorbents for pollutants removal from aqueous solutions. Innovation 2021, 2, 100076.

(17) Liang, L.; Xi, F.; Tan, W.; Meng, X.; Hu, B.; Wang, X. Review of organic and inorganic pollutants removal by biochar and biocharbased composites. Biochar 2021, 3, 255-281.

(18) Rasheed, A.; Carvalho, A.-A.-C.; de Carvalho, G.-G.-A.; Ghous, T.; Nomura, C.-S.; Esposito, B.-P. Chromium removal from aqueous solutions using new silica gel conjugates of desferrioxamine or diethylenetriaminepentaacetic acid. Environ. Sci. Pollut. Res. 2020, 27, $1-10$.

(19) Cornell, R. M; Schwertmann, U. The iron oxides: structure, properties, reactions, occurrences and uses; John Wiley \& Sons: New Jersey, 2003.

(20) Bahmani, P.; Maleki, A.; Daraei, H.; Rezaee, R.; Khamforoush, M.; Athar, S.-D.; Gharibi, F.; Ziaee, A.-H.; McKay, G. Application of modified electrospun nanofiber membranes with $\alpha-\mathrm{Fe}_{2} \mathrm{O}_{3}$ nanoparticles in arsenate removal from aqueous media. Environ. Sci. Pollut. Res. 2019, 26, 21993-22009.

(21) Chiavola, A.; D’Amato, E.; Boni, M. R. Comparison of different iron oxide adsorbents for combined arsenic, vanadium, and fluoride removal from drinking water. Int. J. Environ. Sci. Technol. 2019, 16, $6053-6064$.

(22) Fayazi, M.; Afzali, D.; Ghanei-Motlagh, R.; Iraji, A. Synthesis of novel sepiolite-iron oxide-manganese dioxide nanocomposite and application for lead (II) removal from aqueous solutions. Environ. Sci. Pollut. Res. 2019, 26, 18893-18903.

(23) Sruthi, P.-D.; Sahithya, C.-S.; Justin, C.; SaiPriya, C.; Bhavya, K.-S.; Senthilkumar, P.; Samrot, A. V. Utilization of Chemically Synthesized Super Paramagnetic Iron Oxide Nanoparticles in Drug Delivery, Imaging and Heavy Metal Removal. J. Cluster Sci. 2019, 30, $11-24$.

(24) Khan, F.-S.-A.; Mubarak, N.-M.; Khalid, M.; Walvekar, R.; Abdullah, E.-C.; Mazari, S.-A.; Nizamuddin, S.; Karri, R.-R. Magnetic nanoadsorbents' potential route for heavy metals removal-a review. Environ. Sci. Pollut. Res. 2020, 27, 24342-24356.
(25) Singaraj, S.-G.; Mahanty, B.; Balachandran, D.; Padmaprabha, A. Adsorption and desorption of chromium with humic acid coated iron oxide nanoparticles. Environ. Sci. Pollut. Res. 2019, 26, 3004430054

(26) Ren, T.; He, P.; Niu, W.; Wu, Y.; Ai, L.; Gou, X. Synthesis of $\alpha$ $\mathrm{Fe}_{2} \mathrm{O}_{3}$ nanofibers for applications in removal and recovery of $\mathrm{Cr}$ (VI) from wastewater. Environ. Sci. Pollut. Res. 2013, 20, 155-162.

(27) Tan, W.-K.; Razak, K.-A.; Ibrahim, K.; Lockman, Z. Oxidation of etched $\mathrm{Zn}$ foil for the formation of $\mathrm{ZnO}$ nanostructure. J. Alloys Compd. 2011, 509, 6806-6811.

(28) Deng, J.; Liu, J.; Dai, H.; Wang, W. Preparation of $\alpha-\mathrm{Fe}_{2} \mathrm{O}_{3}$ nanowires through electrospinning and their $\mathrm{Ag}_{3} \mathrm{PO}_{4}$ heterojunction composites with enhanced visible light photocatalytic activity. Ferroelectrics 2018, 528, 58-65.

(29) Ponti, A.; Raza, M.-H.; Pantò, F.; Ferretti, A.-M.; Triolo, C.; Patanè, S.; Pinna, N.; Santangelo, S. Structure, Defects, and Magnetism of Electrospun Hematite Nanofibers Silica-Coated by Atomic Layer Deposition. Langmuir 2020, 36, 1305-1319.

(30) Sun, X.; Sun, X.; Liu, X.; Liu, R.; Li, S.; Shen, M.; Li, Q. Onedimensional $\mathrm{Mg}^{2+}$-induced $\alpha-\mathrm{Fe}_{2} \mathrm{O}_{3}$ nanowires for high-performance supercapacitor. Results Mater. 2020, 5, 100052.

(31) Azeez, N. A.; Dash, S. S.; Gummadi, S.-N.; Deepa, V. S. Nanoremediation of toxic heavy metal contamination: Hexavalent chromium [Cr (VI)]. Chemosphere 2021, 266, 129204.

(32) Rahmat, S.-T.; Chin, O. Y.; Tan, W. K.; Kawamura, G.; Matsuda, A.; Lockman, Z. Hierarchical Porous $\alpha$ - $\mathrm{Fe}_{2} \mathrm{O}_{3}$ Formation by Thermal Oxidation of Iron as Catalyst for Cr (VI) Reduction. J. Phys.: Conf. Ser. 2018, 1082, No. 012044.

(33) Rahmat, S.-T.; Hong, C.-Y.; Budiman, F.; Tan, W.-K.; Kawamura, G.; Matsuda, A.; Lockman, Z. Tailoring Parameters to Produce Nanowires on Metal Surface via Surface Oxidation Process. J. Phys.: Conf. Ser. 2018, 1082, No. 012052.

(34) Srivastava, H.; Srivastava, A.-K.; Babu, M.; Rai, S.; Ganguli, T. Topotaxial growth of $\alpha-\mathrm{Fe}_{2} \mathrm{O}_{3}$ nanowires on iron substrate in thermal annealing method. J. Appl. Phys. 2016, 119, 244311.

(35) Budiman, F.; Bashirom, N.; Tan, W.-K.; Razak, K.-A.; Matsuda, A.; Lockman, Z. Rapid nanosheets and nanowires formation by thermal oxidation of iron in water vapour and their applications as $\mathrm{Cr}$ (VI) adsorbent. Appl. Surf. Sci. 2016, 380, 172-177.

(36) Rahmat, S.-T.; Tan, W.-K.; Kawamura, G.; Matsuda, A.; Lockman, Z. Synthesis of rutile $\mathrm{TiO}_{2}$ nanowires by thermal oxidation of titanium in the presence of $\mathrm{KOH}$ and their ability to photoreduce $\mathrm{Cr}$ (VI) ions. J. Alloys Compd. 2020, 812, 152094.

(37) Onchoke, K.-K.; Sasu, S.-A. Determination of Hexavalent Chromium ( $\mathrm{Cr}(\mathrm{VI})$ ) concentrations via ion chromatography and UV-Vis spectrophotometry in samples collected from nacogdoches wastewater treatment plant, East Texas (USA). Adv. Environ. Chem. 2016, 2016, 152094.

(38) Yuan, L.; Wang, Y.; Cai, R.; Jiang, Q.; Wang, J.; Li, B.; Sharma, A.; Zhou, G. The origin of hematite nanowire growth during the thermal oxidation of iron. Mater. Sci. Eng., B 2012, 177, 327-336.

(39) Taniguchi, K.; Kitazawa, N. Characterization of $\alpha-\mathrm{Fe}_{2} \mathrm{O}_{3}$ nanorod arrays prepared by a quasi-topotactic transformation of solvothermal derived $\beta$-FeOOH nanowire-like arrays. J. Phys. Chem. Solids 2020, 147, 109632.

(40) Ma, H.; Hwang, J.-B.; Chae, W.-S.; Chung, H.-S.; Choi, S.-H.; Mahadik, M.-A.; Lee, H.-H.; Jang, J.-S. Magnetron sputtering strategy for $\mathrm{Zr}-\mathrm{Fe}_{2} \mathrm{O}_{3}$ nanorod photoanode fabricated from $\mathrm{ZrO}_{\mathrm{x}} / \beta-\mathrm{FeOOH}$ nanorods for photoelectrochemical water splitting. Appl. Surf. Sci. 2021, 549, 149233.

(41) Khanna, A. S. Introduction to high temperature oxidation and corrosion; ASM international: Delhi, 2002.

(42) Fujii, C.-T.; Meussner, R.-A. The Mechanism of the HighTemperature Oxidation of Iron-Chromium Alloys in Water Vapor. J. Electrochem. Soc. 1964, 111, 1215.

(43) Lange, N. A. Lange's Handbook of Chemistry; McGraw-Hill: New York, 1985.

(44) Zhu, Y.; He, X.; Xu, J.; Fu, Z.; Wu, S.; Ni, J.; Hu, B. Insight into efficient removal of $\mathrm{Cr}$ (VI) by magnetite immobilized with 
Lysinibacillus sp. JLT12: Mechanism and performance. Chemosphere 2021, 262, 127901.

(45) Roy, A.; Velusamy, S.; Mallick, T. K.; Sundaram, S. Synergistic effect of nanoflower-like CdS for removal of highly toxic aqueous $\mathrm{Cr}$ (VI). Mater. Lett. 2020, 270, 127734.

(46) Alias, N.; Hussain, Z.; Tan, W. K.; Kawamura, G.; Muto, H.; Matsuda, A.; Lockman, Z. Nanoporous anodic $\mathrm{Nb}_{2} \mathrm{O}_{5}$ with pore-inpore structure formation and its application for the photoreduction of Cr(VI). Chemosphere 2021, 283, 131231.

(47) Aredes, S.; Klein, B.; Pawlik, M. The removal of arsenic from water using natural iron oxide minerals. J. Cleaner Prod. 2013, 60, 7176.

(48) Adegoke, H.-I.; AmooAdekola, F.; Fatoki, O.-S.; Ximba, B.-J. Adsorption of $\mathrm{Cr}(\mathrm{VI})$ on synthetic hematite $\left(\alpha-\mathrm{Fe}_{2} \mathrm{O}_{3}\right)$ nanoparticles of different morphologies. Korean J. Chem. Eng. 2014, 31, 142-154.

(49) Hu, J.; Chen, G.; Lo, I.-M. C. Removal and recovery of Cr (VI) from wastewater by maghemite nanoparticles. Water Res. 2005, 39, $4528-4536$.

(50) Liu, Z.; Yu, R.; Dong, Y.; Li, W.; Lv, B. The adsorption behavior and mechanism of $\mathrm{Cr}(\mathrm{VI})$ on 3D hierarchical $\alpha-\mathrm{Fe}_{2} \mathrm{O}_{3}$ structures exposed by (001) and non-(001) planes. Chem. Eng. J. 2017, 309, 815-823.

(51) Zelmanov, G.; Semiat, R. Iron $\left(\mathrm{Fe}^{+3}\right)$ oxide/hydroxide nanoparticles-based agglomerates suspension as adsorbent for chromium $\left(\mathrm{Cr}^{+6}\right)$ removal from water and recovery. Sep. Purif. Technol. 2011, 80, 330-337.

(52) Cao, C.-Y.; Qu, J.; Yan, W.-S.; Zhu, J.-F.; Wu, Z.-Y.; Song, W.G. Low-cost synthesis of flowerlike $\alpha-\mathrm{Fe}_{2} \mathrm{O}_{3}$ nanostructures for heavy metal ion removal: adsorption property and mechanism. Langmuir 2012, 28, 4573-4579.

(53) Gusain, D.; Srivastava, V.; Sillanpää, M.; Sharma, Y.-C. Kinetics and isotherm study on adsorption of chromium on nano crystalline iron oxide/hydroxide: linear and nonlinear analysis of isotherm and kinetic parameters. Res. Chem. Intermed. 2016, 42, 7133-7151.

(54) Jia, Z.; Wang, Q.; Ren, D.; Zhu, R. Fabrication of onedimensional mesoporous $\alpha$ - $\mathrm{Fe}_{2} \mathrm{O}_{3}$ nanostructure via self-sacrificial template and its enhanced $\mathrm{Cr}$ (VI) adsorption capacity. Appl. Surf. Sci. 2013, 264, 255-260.

(55) Nalbandian, M.-J.; Zhang, M.; Sanchez, J.; Choa, Y.-H.; Nam, J.; Cwiertny, D.-M.; Myung, N.-V. Synthesis and optimization of $\mathrm{Fe}_{2} \mathrm{O}_{3}$ nanofibers for chromate adsorption from contaminated water sources. Chemosphere 2016, 144, 975-981.

(56) Zhou, N.; Gong, K.; Hu, Q.; Cheng, X.; Zhou, J.; Dong, M.; Wang, N.; Ding, T.; Qiu, B.; Guo, Z. Optimizing nanocarbon shell in zero-valent iron nanoparticles for improved electron utilization in $\mathrm{Cr}$ (VI) reduction. Chemosphere 2020, 242, 125235.

(57) Richard, F. C.; Bourg, A. C. M. Aqueous geochemistry of chromium: a review. Water Res. 1991, 25, 807-816.

(58) Largitte, L.; Pasquier, R. A review of the kinetics adsorption models and their application to the adsorption of lead by an activated carbon. Chem. Eng. Res. Des. 2016, 109, 495-504.

(59) Foo, K.-Y.; Hameed, B.-H. Insights into the modeling of adsorption isotherm systems. Chem. Eng. J. 2010, 156, 2-10. 